\title{
IES
}

\section{UPDATING THE UK'S CODE FOR FISCAL STABILITY}

Carl Emmerson

Chris Frayne

Sarah Love 


\title{
Updating the UK's Code for Fiscal Stability
}

\author{
Carl Emmerson, Christine Frayne and Sarah Love ${ }^{\dagger}$
}

\begin{abstract}
The 1998 Code for Fiscal Stability sets out the framework within which UK fiscal policy is now set. While having such a code does not make it easier for a Government to meet its fiscal objectives, it may improve the economic credibility of the policy process. To date the Code has generally worked well, and in any case many of the Treasury's practices exceed the minimum requirements of the Code. However, improvements could be made in the light of recent experiences. In particular it would be preferable for less emphasis to be placed on the precise forecasts for fiscal aggregates and greater emphasis to be placed on the magnitude of the risks to those forecasts. Using the projections contained in the March 2004 Budget, and information on the size of errors made in the past, we estimate that there is now a $60 \%$ chance that the Chancellor's "golden rule" will be met without further tax increases or spending cuts. This compares to $74 \%$ for the forecast made by the Treasury 12 months earlier. As well as clarifying how cautious forecasts are, the uncertainty surrounding projections for fiscal aggregates also has implications for the way in which progress towards any fiscal rules should be interpreted.
\end{abstract}

JEL classification: E62, H62

\section{Acknowledgements}

Funding by the ESRC-funded Centre for the Microeconomic Analysis of Public Policy at IFS (grant number M535255111) is gratefully acknowledged. Any errors and all opinions expressed are those of the authors.

$\dagger$ Institute for Fiscal Studies, London. 


\section{Executive summary}

The UK government's aim when introducing the Code for Fiscal Stability in 1998 was to use explicit commitments and openness about performance to enhance the credibility of fiscal policy. Presumably it was hoped that such credibility would improve the farsightedness of fiscal policy-making, and the reputation of the Labour government as a responsible guardian of the public finances, to an extent that outweighed the loss of a completely discretionary fiscal policy.

That belief has been largely fulfilled: the Code has raised standards, particularly with respect to the disclosure of information, without causing a deterioration in those areas where the government's current practice exceeds the Code's minimum requirements.

With respect to the section on 'Transparency', there is scope for the Code to mandate even higher standards of openness without jeopardising the policy-making process or burdening the government unduly. Particular areas for improvement are the ability to withhold information from the public; revisions to costings; the costing of proposals under consideration; and the consistency of data over time.

'Stability' could be enhanced by greater candour about how, exactly, any fiscal rules are to operate. The Code should also refer to the need for monetary-fiscal coordination, of which the government is already aware.

The section of the Code that would benefit most from changes, and where the government perhaps has the most work remaining, is that of 'Responsibility'. An emphasis on accurate rather than cautious forecasts would be welcome. This would be complemented by more discussion of the errors and uncertainty surrounding forecasts of fiscal aggregates. Unless such discussion takes place, the government may not be able to move from a 'hard' hit-or-miss interpretation of its fiscal rules (and the attendant rigidity that such an interpretation brings) to a softer, more probabilistic interpretation (which might allow greater tax and spending smoothing) without a loss of credibility.

The government is already meeting the Code's requirements in the areas of 'Fairness' and 'Efficiency' and, indeed, goes beyond those requirements on many occasions. Ideally, the Code would mandate the publication of certain information about the costs of government policies; the distributional impact of those policies on current and future generations; and the reasons behind the government's decisions about how those policies should be implemented and financed. This would require future governments to maintain at least the present standards in these areas.

Overall, we welcome the beneficial effects of the Code for Fiscal Stability. We find relatively few requirements of the Code that ought to be removed. We believe that, where the government has already gone beyond the requirements of the Code, it is appropriate to raise those requirements to match current practice: there must be no opportunity for standards to fall in the future. In other areas, extending the requirements of the Code would improve the ability of independent commentators to reach informed conclusions about government policy. This should, in turn, improve the quality and accuracy of the information about the public finances that reaches the general public. 


\section{Introduction}

When the present Labour government came to power in 1997, it embarked on a major overhaul and codification of the framework within which the United Kingdom's fiscal and monetary policies are conducted. The Code for Fiscal Stability (CFS) was viewed as a major part of this endeavour. The government first announced its intention to draw up a Code in the November 1997 Pre-Budget Report and made the Code a legal requirement in the 1998 Finance Act. Section 155 of the Act stated: ${ }^{1}$

"(1) It shall be the duty of the Treasury to prepare and lay before Parliament a code for the application of the key principles to the formulation and implementation of-

(a) fiscal policy, and

(b) policy for the management of the National Debt.

(2) The key principles are transparency, stability, responsibility, fairness and efficiency."

The proposed contents of the Code were published in March 1998 and the final version for presentation to Parliament followed in November 1998. The Code can only be amended with the approval of Parliament. It has now been over five years since the Code was implemented, and enough fiscal policy decisions have been taken for us to make a preliminary assessment of where the code has worked well and where further improvements could be made. During this time, the Code has been neither revised nor evaluated by the government. No other work has assessed it. ${ }^{2}$ This paper therefore presents a timely and constructive analysis of (i) how well the Code fulfils the requirements of the Finance Act in theory and (ii) how successful at improving fiscal policy the Code has been in practice.

Section 2 of the paper reflects on whether or not a formal code was necessary. Section 3 then considers the five principles of fiscal management that the Code was intended to explicate. These principles - transparency, stability, responsibility, fairness and efficiency - are set out in the CFS (paragraphs 3 to 8). The section addresses the following questions:

- Was each principle defined and explained appropriately in the Code?

- Did the Code fail to specify anything that governments need to do to abide by each principle?

- Did the Code include anything that was not needed for, or likely to hinder rather than aid, the implementation of each principle?

Section 4 discusses what the principles underlying the Code for Fiscal Stability can tell us about the choice and assessment of appropriate fiscal rules. Section 5 concludes.

\footnotetext{
${ }^{1}$ Source: HM Stationery Office (1998), Part VI.

2 Buiter (2001) is more an assessment of the specific fiscal rules than of the overall Code.
} 


\section{Is a Code for Fiscal Stability necessary?}

\subsection{Introduction}

Since the early 1990s an increasing number of countries have introduced codes or frameworks within the constraints of which fiscal policy is conducted - setting out general practices and specific aims for the management of the public finances. At the forefront of these countries was New Zealand, which introduced its Fiscal Responsibility Act in 1994. Since then both developed countries such as Australia, Canada, the member states of European Union and emerging economies such as Argentina, Brazil and Peru have followed suit and introduced their own codes. It is in the context of this trend for fiscal frameworks that the UK government, already a signatory of the EU's Stability and Growth Pact, introduced the Code for Fiscal Stability in 1998.

\subsection{Policy frameworks for monetary policy}

This introduction of fiscal frameworks follows the longer established practice of monetary frameworks and codes. These have evolved from ranges for countries' exchange rates, through tight controls on the increase in the money base to the current trend for specific targets for the rate of inflation and requirements to use the tools of monetary policy to guide the inflation rate to stay consistent with the targets set. Alongside targets for monetary aggregates, many governments have gone even further in setting up a framework which constrains the way that policy is determined, by delegating the management of the policy to an independent central bank rather than keeping it at the discretion of ministry of economics or finance.

The rationale for setting up a framework within the constraints of which monetary policy is determined and delegating to an independent authority rests firmly on economic theory. As inflation is in part fuelled by prior expectations of inflation (for example through expectations guiding pay settlements), a government can use a monetary target to influence these expectations. As long as the government's monetary target can be committed to credibly, expectations of inflation attaining its target level will in themselves create conditions favourable to that level of inflation being realised. Committing to a particular level of inflation through a code appears to be more effective than pursuing an ad hoc discretionary strategy that is liable to frequent change, precisely because of the importance of expectations. In addition, ensuring the level of credibility that is required for such targets to be effective may be difficult. Based on the economic argument that governments cannot credibly commit to such targets just by stating them ${ }^{3}$ Kenneth Rogoff showed, in 1985, that delegating their functioning to an independent establishment can overcome this problem; this is practised in a large number of countries.

For monetary policy, a framework for making decisions is considered necessary to overcome issues specific to the nature of inflation, which is outside the direct control of

${ }^{3}$ See Kydland and Prescott (1977) and Barro and Gordon (1983) 
the government and the realisation of which is directly linked to beliefs and the credibility of government pronouncements. Fiscal policy differs significantly from monetary policy in these respects; at least for developed countries there is no such direct link between the credibility of fiscal aims and their realisation except in terms of the effect they may have on government departments' requests for cash and voter pressure for lower taxes or higher spending. Ultimately, given that the government has control over tax rates, the generosity of transfer payments and the level of spending on public services, both the decisions and therefore the outcomes rest with the government in a way that the inflation rate does not and its pronouncements are at best indirectly linked to its ability to deliver them. Still, arguments invoking credibility and the need for specific aims are nevertheless used to make the case for fiscal frameworks. The reason for this is that there are ways in which completely discretionary management of fiscal policy may be suboptimal because of the nature of how decisions are made and how outcomes are viewed.

\subsection{What are the potential problems with completely discretionary fiscal policy?}

Much as the introduction of monetary frameworks served to rectify issues of credibility and expectations in monetary policies, so the arguments for fiscal frameworks rely on the belief that there are difficulties in making fiscal policy that ought to be addressed.

One such difficulty stems from the importance of adequate scrutiny of the party in office in a democratic society. Assessing a government's record on fiscal policy in the absence of firm guidelines can be complicated. Overall fiscal outcomes are judged on a combination of current spending, capital spending and tax receipts. But they are also affected by aspects largely outside the government's control, such as the position of the economy in the economic cycle, shocks to the world economy, and the levels of debt and deficit left from previous years, so it can be difficult to reach a comprehensive and comprehensible assessment of a government's record on the public finances. Given that the electorate's view of a government's record in office affects the decision regarding who forms the next government, it is particularly important to be able to structure the debate in a manner that avoids perceptions being formed by 'sound bites' focussing on fiscal outcomes selected retrospectively to promote a political opinion.

The advantages that the government has over the public in understanding fiscal policy are the information at its disposal, a deeper understanding of the issues, and more time and energy to devote to thinking about the record and direction of fiscal policy. Within any set of fiscal outcomes that are achieved at any particular time, some will reflect more favourably on the government than others - either due to policy decisions or a result of effects outside the government's control. Being selective about which of these aspects to concentrate on has naturally long been the practice of government and opposition members, as well of journalists and commentators with varying degrees of independence and understanding of the issues. The effect this has on the political process can be confusing and can hinder the efficient functioning of the electoral process by creating a smokescreen between perceptions and reality.

There are also issues relating to the incentives that governments face in their management of the public finances. When setting fiscal policy, the government chooses 
a certain amount of public spending and funds that spending through one or both of taxation and borrowing. One of the politically appealing characteristics of borrowing is that it allows spending without financing that spending out of current tax revenues, and therefore shields current voters from bearing the full cost of the publicly funded goods and services they consume. Over the medium term, not only must this borrowing be paid back, but it can also be a source of other costs (such as the need to divert resources to service the interest on the debt). A responsible government would ensure that it maintained stability and took into account the legacy that its spending, taxation and borrowing choices leave. But governments know that they may not be in power when the medium-term impact of their decisions becomes apparent, so they may be tempted to 'buy' electoral success with borrowing-financed spending and leave their successors to deal with the resulting debt. So a 'political business cycle' develops, encouraging shorttermism at the expense of choices that take full account of the longer-run consequences.

\subsection{Are these problems sufficiently important to justify rules?}

But are concerns about the incentives governments face important enough to merit specific intervention in the field of fiscal policy? After all, neither fiscal policy nor the running of a country's economy differs significantly from other policy areas with respect to potential conflicts of interest between the politically appealing choice and the option that takes long-term consequences into account, or the ability of the electorate to discern fully the consequences of government policy to reach its own verdict on the handling of policy. One reason for particular interest in this area is the fact that bad management of fiscal policy has the potential to affect all members of a society in terms of higher taxes or spending cuts, and these are areas that the voting public typically attach high importance to.

From the point of view of the political parties, the ability to 'spin' the health of the economy can be both helpful and damaging. A party with a previously unfavourable record on this front - or a record that is perceived by the electorate as unfavourable may wish to start with a clean slate and prove that it is able to pursue policies that do not have damaging consequences in the future. Yet just as bad policy may be disguisable, so good policy may be hard to prove. The ability to show that serious concern was paid to economic policy, and that the outcomes showed responsibility and ensured the health of the public finances, can be valuable to a party that is prepared to campaign on the basis of such planning, or that feels it would be strongly penalised for failing to do so. Indeed, the idea of signalling a commitment to sensible management of the public finances was an important part of the reason why the UK now has a fiscal code. When announcing the proposal to introduce a Code for Fiscal Stability, Gordon Brown stated, "The Code demonstrates further the Government's commitment to a commonsense approach to managing the public finances. By publishing a Code we will be bringing openness and credibility to fiscal policy in a way that no other British Government has ever done". ${ }^{4}$

\footnotetext{
${ }^{4}$ HM Treasury press release (http://archive.treasury.gov.uk/pub/html/prebudgetNov97/hmt2.html) accompanying the November 1997 Pre-Budget Report.
} 


\subsection{Is a fiscal framework required to alleviate these issues?}

The introduction of a fiscal framework is one approach to attempt to alleviate some of these issues. Setting out an explicit code of conduct can serve to focus the debate on fiscal policy to within parameters that can be judged more easily and coherently than undertaking an overall assessment of a government's record on fiscal policy on an ongoing basis. It can reduce the scope for both the government to focus selectively on aspects of policy that reflect more favourably on it in retrospect and for only selective aspects of fiscal policy to make it into the public debate. Also, it can focus debates between the party in government and the opposition on aspects of policy that are seen as being key, making the arguments made on both sides more directly comparable to each other and therefore understandable.

For a government intent on proving that it is a responsible guardian of fiscal policy, setting out a fiscal code can help it show that it is sticking to long-term priorities when managing the public finances and keep to commitments that are not determined by short-term pressures. By setting out its fiscal policy aims and sticking to them, the government should be better able to argue its case for competent long-term economic management in a coherent way. A framework can therefore provide it with the means to gain concrete credibility.

Of course, while the introduction of code can achieve these aims, it is not obvious that the introduction of a code will achieve them, nor that not having a code makes it impossible to do so. To achieve these aims, it must be a credible code, with widespread acceptance for the aims it is seeking to achieve and a belief that the public will be able to judge the government's performance against the code in a straightforward manner. Where this is the case, the introduction of the code is in itself the first signal that a government is serious about its approach to fiscal policy. Whether it is able to build on that first boost will depend on how good the code is seen to be over time and on whether the government is seen to be operating a fiscal policy that is consistent with its stated objectives.

The fact that the act of introducing a code can be a signal of a government's intentions in terms of its management of fiscal policy can work both in favour of and against the credibility of the code. A government that is seen as profligate and opportunistic in its use of discretionary fiscal policy will face an uphill struggle to convince the public of the 'water-tightness' of its code. While setting out the parameters within which fiscal policy will operate centres the debate, there needs to be consideration given regularly to whether its structure continues to reassure the public about the management of fiscal policy and whether the spirit of the code is present in the conclusions drawn about whether policy has been consistent with it.

Conversely, of course, a government or country can build up a reputation over time without the use of a code. This does not overcome the issue of whether it has sufficient incentive to continue to do so, but such a track record will serve to reassure the public. For reasons pointed out earlier, such a reputation can only be built up over a long time. Therefore, while the introduction of a fiscal code or framework is by no means necessary, it is a useful tool for moving to an environment of long-term sensible fiscal 
management while providing the means for the government which does that to be rewarded with credibility.

As the UK has already implemented its own Code for Fiscal Stability it might be very difficult for a future government to remove or substantially loosen the Code without significant loss to its economic credibility. Hence in the next section we turn to the specifics of the current code and suggest where potential improvements could be made. These are addressed by each of the Code's stated underlying principles: transparency, stability, responsibility, fairness and efficiency.

\section{How could the Code for Fiscal Stability be improved?}

\subsection{Transparency}

The Code for Fiscal Stability states (paragraph 4) that:

"The principle of transparency means that the Government shall publish sufficient information to allow the public to scrutinise the conduct of fiscal policy and the state of the public finances, and shall not withbold information except where publication of that information would:

a. substantially harm:

i. $\quad$ the national security, defence or international relations of the United Kingdom;

ii. $\quad$ the investigation, prosecution, or prevention of crime, or the conduct of civil proceedings;

iii. $\quad$ the right to privacy;

iv. the right of other parties to undertake confidential communications with the Government;

v. the ability of the Government to undertake commercial activities; or

b. harm the integrity of the decision-making and policy advice processes in Government."

\section{Publishing and withbolding information}

Information is essential if independent commentators are to be able to conduct a meaningful audit of the government's fiscal policy. It may not always be appropriate or possible for the government to publish all information on fiscal policy, but it is welcome that the Code makes clear that publication should be the default. It is equally welcome that the Code recognises that transparency can conflict with other objectives, and that in light of this problem - it lists explicitly the circumstances that justify the withholding of information in clause (a). However, because withholding information should take place only in exceptional situations, it is worrying that the Code also includes clause (b), which allows withholding of information whenever publication would "harm the integrity of the decision-making and policy advice processes in Government". Such a clause essentially represents a catchall reason that any chancellor could, if he or she were so minded, use to evade close scrutiny of his or her policies. The presumption that the "integrity of the decision-making and policy advice processes" is best protected by not 
disclosing information about how policies were decided upon, how much they are likely to cost and estimates of their likely impact is also questionable. It is preferable for clause (b) to be removed altogether.

This is not to suggest that there are no reasons why information might have to be withheld other than those listed in clause (a). For instance, if the Treasury were predicting a sharp downturn in house prices and were incorporating this prediction into their forecast of stamp duty revenues, it might be sensible not to publish their prediction in case it became self-fulfilling (whereas they might prefer it to turn out to be unduly pessimistic). But reasons such as the potential for serious harm to the wider economy should be added individually to the list in clause (a), not used as a pretext for adding a separate, and poorly defined, caveat. Given that there is no requirement for the government to tell us that it is withholding information, so we are never in a position to know whether or not one of the reasons listed in the clauses has been invoked, it is important that information is only withheld on rare occasions, when it is necessary to guard against a specific threat, not just when its publication would cause the government embarrassment or inconvenience. This would improve further the integrity of the decision-making and policy advice process.

In addition, it would be helpful for the government to provide as much advance notice about the release dates of fiscal information as is possible. The International Monetary Fund's 'Revised Code of Good Practices on Fiscal Transparency', which is intended to be "a standard of fiscal transparency to which all countries should aspire", includes a paragraph stating that, "Advance release date calendars for fiscal information should be announced." 5 The Office for National Statistics produces a calendar showing the dates of forthcoming statistical releases but there is currently no obligation for the Treasury or any other government department publications to give advance notice of the dates of statistical publications. The dates of Pre-Budget Reports and Spending Reviews in particular are often announced with very little notice.

\section{The presentation of costings}

In line with the CFS's transparency requirements, the government itemises in each Budget and Pre-Budget Report the expected cost of new policy announcements over the next three years. ${ }^{6}$ But the Code fails to specify how the costings should be broken down, the number of years for which costings should be published, and - most importantly there is no requirement for significant revisions to previously published costings to be disclosed.

To ensure that the information available to the public is maximised, the Code ought to specify that costings must be divided clearly into items that count as (positive or negative) taxation and items that count as expenditure. Where an item falls under both headings, the percentages of the item's value that score as tax and spending should be

\footnotetext{
${ }^{5}$ IMF (2001)

${ }^{6}$ For an example of this, see Tables A1 and A2, pp.186-188, of HM Treasury (2004).
} 
given. It seems appropriate for the Code also to specify explicitly that, as is current government practice, costings should be provided for at least the next three financial years. Where the three-year horizon does not provide an accurate reflection of the annual full-year cost, the Code should specify that an estimate of the full year's costing be published. One example of when the government did this voluntarily was the March 1999 Budget. This announced some details of the Research and Development tax credit for small-and medium-sized firms. As is usual, costings were published for the next three financial years - in this case, 1999-2000, 2000-01 and 2001-02. As the policy was not to be introduced until April 2001, these were zero for the first two financial years and $£_{1} 100$ million in 2001-02. However, as $£, 100$ million did not represent the true full-year cost of the policy, the Budget also published the fact that the full effect (of $£ 150$ million) would be felt in 2002-03. It would be sensible for the CFS to state that this good practice should always be required. The long-run costings of policies - such reforms to the state pension system - should also be published. This is discussed in more detail in section 3.4 on fairness.

The IMF's 'Revised Code' states that, "Budget data should be reported on a gross basis, distinguishing revenue, expenditure, and financing, with expenditure classified by economic, functional, and administrative category. Data on extrabudgetary activities should be reported on the same basis." The current UK practice does not always comply with this. The Code should make it obligatory to itemise separately the effect that each policy, or group of related policies, will have on each individual tax or spending item, rather than publishing a total cost that is spread across different taxes and spending items. Although the costings published in Budgets and Pre-Budget Reports are usually diligent in this respect there have been instances when items have been grouped together in an unhelpful manner. For example, the costings table in the 2002 Budget included the indexation of the Working Families' Tax Credit and the Disabled Persons' Tax Credit as one item, ${ }^{8}$ despite the fact that the two tax credits count as separate items and both count partly as spending measures and partly as a reduction in tax revenues. Costings should, where possible, avoid presenting items "net of" other taxes or spending items or in a way that makes it complicated to interpret how they affect the overall tax and spending changes in a Budget. For instance, Table A1 of Budget 2004 contains a footnote showing the expected revenue gains from a "Direct taxes compliance package" net of additional resources allocated to the Inland Revenue. The footnote does not indicate how much more has been allocated to the Inland Revenue. ${ }^{9}$

Finally, the government should be obliged, at a minimum, to publish revised costings for any policy if the estimate of its cost has changed by more than a certain amount since the costing was last published. An example of a policy whose costings probably changed significantly over time was the July 1997 Budget decision to abolish dividend tax credits payable to non-taxpayers. This was forecast in 1997 to raise $£^{5}$.4bn in 1999-2000 and the amount was not revised despite more up-to-date information becoming available -

\footnotetext{
${ }^{7}$ See HM Treasury (1999), Table 1.11, p.112, for the first three years' costings and page 116 for the full year costing.

${ }^{8}$ See Table A2, p.156, of HM Treasury (2002).

${ }^{9}$ See HM Treasury (2004), p.186.
} 
not least the subsequent large rise (then large fall) in the stock market, which presumably affected the policy's value. If requiring the Treasury to publish new costings only after significant cost changes to proved ineffective, the Code could require the Treasury to publish on its website the latest costings of all policies introduced in the last 5 years. If there were no costing revisions, this would be easy to comply with - in fact, by having electronic copies of previous Budgets online, the Treasury would currently be complying already.

To the government's credit, it has revised its initial costings in some instances. In Budget 2002, the cost of the new $0 \%$ rate of corporation tax on firms with small profits was put at $£ 450$ million in 2004-05. Two years later, the revised costings in Budget 2004 implied that the actual cost in 2004-05 was now expected by the Treasury to be $f 880$ million, ${ }^{10}$ ie, almost double what was originally forecast.

With respect to spending done under the Private Finance Initiative (PFI), which involves long-term commitments to purchase goods or services, the government publishes in each Financial Statement and Budget Report (FSBR) breakdowns by department the amount of capital spending to be done by the private sector over the next three years. This is presented separately for deals already signed and those that are at the preferred bidder' stage. The FSBR also publishes the annual payments from the public sector to the PFI operators over the next 25 years. The information published about PFI spending is generally very good, and should be required explicitly by the CFS.

However, with respect to the relationship between PFI spending and conventional public sector net investment, there is a lack of clarity about what proportion of the capital spending by the private sector under PFI contracts is already 'on balance sheet' ie, is already included in the figures for public sector net investment and hence public sector net borrowing and public sector net debt. In June 2003 just over half of capital spending financed through the PFI was included on the Government's balance sheet. ${ }^{11}$ It would be informative for the FSBR to publish this proportion for each year and department. As well as publishing tables for capital spending over the next three years, the government should also have to publish the total amount of capital spending that each department has incurred under PFI schemes over all years to date. The CFS should also require a list of all PFI schemes and their costs to be published in one place. As information on all PFI projects is already on the Treasury website, this should not be an onerous task.

\footnotetext{
10 The figure of $f_{8} 880$ million was not published explicitly in the Budget. Instead, the Treasury published a gross estimate of the expected gains from the new $19 \%$ minimum tax on distributed profits, which was $£ 10$ million in 2004-05, and a net gain from the new 19\% rate after taking into account the loss in revenue arising from the unexpected increase in incorporation of small businesses since the $0 \%$ rate was introduced, which was $-£, 420$ million in $2004-05$. This implies that the gross loss from the $0 \%$ tax rate was $£ 430$ million ( $£ 420$ million plus the net $£ 10$ million recouped by the new minimum tax). Because this loss is relative to what was already expected by March 2004, it is in addition to the $£ 450$ million that was already factored in from the 2002 Budget. See Table A1, pp.186-7, of HM Treasury (2004).

11 The figure of 57\% was made available in June 2003. See speech by Paul Boateng, Chief Secretary to the Treasury, http://www.hm-treasury.gov.uk/newsroom and speeches/speeches/chiefsecspeeches/speech cst_100603.cfm for details.
} 
In addition to PFI, the government has various other ongoing liabilities that are not counted within the public sector net debt total or itemised under the costings. These range from bonds to finance the Channel Tunnel Rail Link, which the government underwrote but regards as unlikely to need the guarantee, to borrowing carried out by entities such as Network Rail. Network Rail is classified as a private non-financial company because, on the criteria used by the Office for National Statistics, it is no longer publicly controlled. ${ }^{12}$ However, the company's importance to the provision of rail transport is such that if it were to be in financial straits, it is not implausible that the government would assist it. For instance, the indirect governmental backing that Network Rail received via the Strategic Rail Authority was appears to have been important to the success of its $f_{1} 10 \mathrm{bn}$ refinancing package in February 2004. ${ }^{13}$

The Code currently requires the government to include in its economic and fiscal projections (paragraph 20) "an analysis of the risks surrounding the economic and fiscal outlook, including Government decisions and other circumstances that have still to be quantified with certainty [and] other material contingent liabilities". This requirement is not quite as comprehensive as that suggested by the IMF's 'Revised Code', namely, "Statements describing the nature and fiscal significance of central government contingent liabilities and tax expenditures, and of quasi-fiscal activities, should be part of the budget documentation." It is unrealistic to ask the Treasury to produce an exhaustive list of the public sector's contingent liabilities, as such a list would have to cover the costs of coping with every possible kind of future emergency. We also realise that if the Treasury listed certain potential liabilities on its balance sheet, this might create moral hazard problems. But it would be preferable for the word "material" to be removed from the above sentence, and for the Code to emphasise that the Treasury should publish as many details as possible of its contingent liabilities. The qualification that liabilities only have to be analysed if they are "material" is ambiguous - does the Code mean that the liabilities have to be of a certain size or a certain type, or that they have to have a certain probability of occurring, to be included? It also fails to emphasise that, while there are numerous liabilities that are always present but which the Treasury cannot affect (natural disasters, attacks, etc), there are also liabilities that the Treasury chooses to incur voluntarily, like underwriting the debts of companies such as Network Rail. Even if the Treasury cannot publish information about the former, it can about the latter.

\section{Forthcoming policies and policies under consideration}

Even if the government were to disclose all costings of new policies, and all revisions to old costings, in line with our recommendations above, such costings will not give the public an accurate impression of the likely state of the public finances if equivalent information on policies that are under serious consideration is not placed in the public domain. While it would be impractical for the government to cost fully every single policy proposal - and doing so might increase public confusion and uncertainty about

\footnotetext{
${ }^{12}$ For more information on the classification of Network Rail, see http://www.statistics.gov.uk/about/Methodology by theme/rail network/default.asp.

${ }^{13}$ See http://www.statistics.gov.uk/pdfdir/netrl0204.pdf and http://news.bbc.co.uk/1/hi/business/3497110.stm.
} 
fiscal policy - it seems reasonable that policies that have significant implications for the public finances, and that the government is seriously considering implementing, should be costed and the costings should be published. Examples of such potential policies include manifesto commitments, draft legislation, forthcoming legislation and commitments made in ministers' speeches.

The Code does in fact require the Pre-Budget Report to "include, so far as reasonable practical, proposals for any significant changes in fiscal policy under consideration for introduction in the Budget" (paragraph 15). The Code also requires the Treasury to include in its projections "Government decisions and other circumstances that have still to be quantified with certainty" (paragraph 20) and, "where the fiscal impact cannot be quantified with reasonable accuracy by the day the projections are finalised, these impacts should be noted as specific fiscal risks" (paragraph 23). But this allows the Treasury merely to state that certain items have not been included and should be taken account of, without any attempt to indicate their magnitude. For example, the forecasts contained in the November 2001 Pre-Budget Report did not take into account the consultation that eventually led to the introduction of the Working Tax Credit and the Child Tax Credit - to comply with the Code all that was required was for it to be noted that these risks had been excluded. ${ }^{14}$ The overall cost of these tax credits was far from insignificant: the subsequent April 2002 Budget put the cost of these items at $\AA_{0} 0.5 \mathrm{bn}$ in 2002-03, $f^{2.5 b n}$ in 2003-04 and $f^{2.3 b n}$ in 2004-05. ${ }^{15}$ Even a crude estimate of the costs would have been preferable to none whatsoever. The fact that Brewer, Clark and Myck (2001) were able to estimate in October 2001 that the new tax credits were likely to cost about $f^{2} .1 \mathrm{bn}$ a year to introduce - a prediction that proved to be reasonably accurate - suggests that it would have been possible for the Treasury to have published similar estimates of the costs of the tax credits at an earlier stage. ${ }^{16}$

If the Treasury were unable to give provisional costings because the generosity and/or coverage of a policy had yet to be decided, they could publish a range of estimates would instead, thus providing a 'ready reckoner' of potential valuations. For instance, with respect to Labour's 2001 manifesto commitment to introduce a 'Child Trust Fund', the Treasury could have stated that there are about 750,000 births each year in the UK, so every $£, 100$ put in each child's fund would cost the government approximately $£, 75$ million a year. One example of a policy change for which such a 'ready reckoner' was produced is the Climate Change Levy introduced in the 1999 Budget. The government requested in March 1998 a report from Lord Marshall about how economic instruments might be used to promote energy efficiency in business. Lord Marshall's report was published as an associated document to the 1998 Pre-Budget Report. Annex F of the report (entitled 'Estimates of emissions reductions in response to economic instruments') included a table showing alternative estimates of the long-run elasticity of the energy demand of industry. The Annex also provided an illustrative calculation of what reduction in carbon dioxide emissions would result from a tax worth $£$, bn a year

\footnotetext{
${ }^{14}$ See paragraph B23, p.170, of HM Treasury (2001).

${ }^{15}$ See Table A.1, pp.154-155, of HM Treasury (2002).

${ }^{16}$ See http://www.ifs.org.uk/taxben/taxcred.pdf for details of the IFS's predictions.
} 
and included a similar illustrative calculation from an independent economics consultancy. ${ }^{17}$

\section{Consistent data}

A government could publish generous quantities of information about its forecasting techniques, its assumptions and the costs of past, present and forthcoming policies in each Pre-Budget Report and Budget. However, if the methodology it used to calculate and present fiscal data changed from one publication to the next, without any explanation of how to reconcile the different data series, then despite being in full compliance with the Code, the government should have done more to enable public scrutiny of fiscal policy.

We do not wish to 'lock' governments into existing methodologies and prevent them from improving the quality of publicly available data. Indeed, many of the recent changes to the way in which fiscal data are presented, such as the shift from cash-based accounting to resource-based, accruals accounting, have been made for very good reasons. But it is important that comparability with past years' data is preserved. To this end, we would include in the Code a clause stating that any change in the government's accounting or data presentation methodology should, where possible, be accompanied by an explanation of how to convert data from the old to the new format and by the republication of a reasonable run of historical data that is consistent with the new format. If this is not possible, the government should have to publish information on the previous basis as well as the new basis for a period of at least 3 years.

One example of the problems caused by a lack of consistent data is the relatively recent change to the measurement of public spending and how it is subdivided. Prior to 1998, General Government Expenditure (GGE) was split into a Control Total and cyclical items. Since 1998, a new measure of public spending, known as Total Managed Expenditure (TME), has been used. This is been divided into Departmental Expenditure Limits (DEL) and Annually Managed Expenditure (AME). TME is not the equivalent of GGE because the former includes public corporations as well as central and local government, whereas the latter does not. Helpfully, the Treasury has published a consistent series of TME running back to 1963-64. DELs and AME are different to the old Control Total and cyclical spending. Unhelpfully the Treasury's data on the DEL/AME split of TME extends back only to 1998-99, with no indicative splits for previous years. This means that, for example, it is not possible even to calculate the growth in DEL or AME since Labour came to power in May 1997, let alone make comparisons with other parliaments.

\subsection{Stability}

The Code for Fiscal Stability states (paragraph 5) that:

\footnotetext{
${ }^{17}$ See Marshall, C. (1998), p.61.
} 
"The principle of stability means that, so far as reasonably practicable, the Government shall operate fiscal policy in a what that is predictable and consistent with the central economic objective of high and stable levels of growth and employment"

\section{Minimising unpredictability}

It is neither possible nor desirable for the government to avoid any disruption to, or change of, fiscal policies. The performance of the economy and the government's political priorities can both change rapidly and suddenly. It is possible, however, to minimise the shock associated with the fiscal response to such changes. In other words, the government's reaction to a change in its circumstances should be relatively easy to predict.

To achieve such predictability, the government needs to announce in advance how it intends to react to certain circumstances. This is why it is important that if the government uses fiscal rules to implement the Code, it publishes in advance three key pieces of information:

- how, exactly, the rules will be met;

- what will happen if they are not met/ not on course to be met;

- and when it will happen by.

With respect to "how the rules will be met", the government must specify how the rules will be assessed to a level of detail that leaves no ambiguity about the methodology being used. For example, the 'golden rule' states that the current budget surplus must be at least zero over an economic cycle but there are several ways in which the rule could be assessed: the cash amounts of current budget surpluses and deficits could be summed or the current budget surpluses, expressed as a share of national income, could be averaged, to mention but two possibilities. The government clarified in HM Treasury (1999b) that they were using the latter method. ${ }^{18}$ However some ambiguity still remains over the sustainable investment rule: While Budget 2004 states that "To meet the sustainable investment rule with confidence, net debt will be maintained below 40 per cent of GDP in each and every year of the current economic cycle", ${ }^{19}$ it is unclear whether over future economic cycles net debt will need to be below 40 per cent of GDP in every year or just on average over the whole economic cycle.

In terms of "what will happen if they are not met", the government should be obliged to explain what corrective action it would take (if any) should one or more fiscal rule be breached. This does not mean that the government would be obliged to take corrective action whenever a rule was broken, regardless of the circumstances. If, for instance, the Treasury expected to meet a rule with a year to go, but it transpired at the end of the year that the forecast had been overoptimistic, it would be inappropriate for the Code to

\footnotetext{
${ }^{18}$ See HM Treasury (1999b) paragraph 4.8.

${ }^{19}$ HM Treasury (2004), paragraph 2.58.
} 
require the Treasury to impose tax increases. In some circumstances, it would be reasonable to allow the rule to be broken so long as there was an examination of the reasons why the forecast had proved overoptimistic. Specifying what ought to happen, under most circumstances, when a fiscal rule either has been broken or is on course to be broken, need not remove all flexibility. Finally, regarding "when corrective action will happen by", it is particularly important that the government lay out a time frame, especially for rules that are forward-looking and have no particular 'deadline' by which they must be met. Stating that corrective action will be taken if a fiscal rule is breached (or is expected to be breached) does not aid predictability unless the public knows when the corrective action will be taken. If it is possible for the government to forecast that a fiscal rule is likely to be missed in future years but to take no action and offer no explanation as to why it is not taking action, the credibility of the fiscal rule is undermined and public uncertainty is increased.

We do not want the government to be forced never to deviate from its preannounced behavioural rules regardless of the circumstances. There may be instances in which unexpected fiscal policy changes, such as allowing fiscal rules to be broken despite promises to the contrary, are preferable to predictability. Alternatively, the Government might decide to take a different action to the default one to ensure that its fiscal objectives are met. We would therefore prefer to modify the Code so that it requires the government to spell out in detail how it intends to respond to changes without making those intended responses binding. Perhaps, much as the Bank of England has a mandated band for inflation but should inflation stray outside the band then the Governor of the Bank of England has to write an 'open letter' explaining the Monetary Policy Committee's reasons for so doing, the government should be able to deviate from its intended response to a given circumstantial change (such as a fiscal rule being broken) so long as it offers some explanation for doing so.

It is worth noting that our suggested modifications to the Code represent only a slight tightening of the existing requirements. Paragraph 11 of the CFS specifies that:

"The Government may depart from its fiscal objectives and operating rules temporarily provided that it specifies:
a. the reasons for departing from the previous fiscal policy objectives and operating rules;
b. the approach and period of time that the Government intends to take to return to the previous fiscal policy objectives and operating rules; and
c. the fiscal policy objectives and operating rules that shall apply over this period."

So the government already has to make its fiscal rules clear and to explain itself when it does not try to meet them. Our recommendations would simply require greater clarity about how the rules are assessed and what the government ought to do when it appears to be unlikely to meet them. 


\section{Monetary-fiscal coordination}

The Bank of England Act, which was passed - like its fiscal counterpart - in 1998, laid out the operation of monetary policy in considerable detail. The Act mandated that the principal objective of the Bank should be price stability and specified the structure, composition and frequency of meetings of the Bank's Monetary Policy Committee (MPC). It is, of course, possible for a future government to amend the Act so as to change the objectives of, or control over, monetary policy. For example, such a change would be required if the UK were to join the European Monetary Union. However, the fact that the Conservative party has endorsed the present framework ${ }^{20}$ suggests that there is a cross-party consensus, at least for now, in favour of the Bank's operational independence and remit. So we shall, for the purposes of this paper, take the arrangements in the Bank of England Act as a 'given' and consider what they imply for the conduct of a stability-promoting fiscal policy.

It is surprising that the CFS states explicitly in its paragraph on stability that this includes making fiscal policy decisions that are "consistent with the central economic objective of high and stable levels of growth and employment" without making any reference to fiscal-monetary policy coordination, or how high growth and employment relate to the Bank of England's objective of price stability. In their analysis of Britain's macroeconomic framework, Balls and O'Donnell (2002) state, "In the UK where the Treasury sets both the fiscal and the monetary policy objectives it clearly makes no sense for the MPC to renege on its operational task of hitting the symmetric inflation target. Fiscal policy is constrained by the fact that the MPC is required to ensure that monetary policy counteracts any inflationary consequences of fiscal policy that would otherwise cause inflation to deviate from target, thereby limiting any potential gain to the Government from a profligate fiscal expansion." In other words, the MPC's likely reaction to expansionary fiscal policies could help to constrain the Treasury. There is also a Treasury representative at each monthly MPC meeting to alert the MPC to any fiscal developments that might affect the inflation outcome.

All of the comments made above, as to how clarity about the operation of the fiscal rules and the government's response to changes in circumstances should aid predictability for the public, apply equally to fiscal-monetary coordination. The sooner that the MPC is notified of the outlook for fiscal policy and the more predictable that outlook is, the less likely it is that there will be any surprises that might require a significant change in interest rates.

The fact that the MPC is obliged to keep inflation within a certain band should discourage the Treasury from formulating a fiscal rule that might require abrupt shifts in fiscal policy, even if those shifts were in line with a publicised and clear 'fiscal reaction function' (to use the Balls and O'Donnell terminology). If, for example, the government had a fiscal rule requiring it to achieve a certain current budget surplus over the course of the economic cycle and to correct any failure within a year of the cycle's end, an

\footnotetext{
20 Speech made by Michael Howard, the then Shadow Chancellor of the Exchequer, "The Limits of Economic Consensus? Thoughts on Fiscal Policy", 12th April 2002.
} 
unanticipated receipts disappointment in the last year of the cycle could require the government to tighten fiscal policy abruptly. This previously unanticipated tightening might, in turn, require the MPC to cut interest rates to keep inflation within the mandated band. The result could be two simultaneous, temporary policy changes. Obviously, the likelihood of such a tightening being completely unanticipated by the MPC is reduced by the fact that the Office for National Statistics/HM Treasury jointly publish monthly public sector financial data, which enables disappointing receipts or unexpectedly high spending to be picked up before the end of the financial year. Also, the MPC could choose not to loosen monetary policy in the face of a temporary tightening of fiscal policy, but to accommodate the loosening instead. However, the fact remains that under certain fiscal rules, forecast errors could necessitate sudden responses. To encourage governments not to make fiscal rules with a tendency to cause substantial policy swings, a sentence requiring the government to set its fiscal policy rules in light of the Bank of England's monetary policy response function would be helpful.

The MPC uses the government's spending projections and revenue projections to inform its Inflation Report forecasts. This reinforces the need, discussed in the following 'Responsibility' section, for forecasts to be based on realistic, central assumptions and for forecast errors to be published and uncertainties quantified. To the Treasury's credit, it "puts a lot of emphasis on comparing the projected fiscal balances with those contained in its most recent publications". ${ }^{21}$ It is particularly important for the Treasury to disclose to the MPC any key assumptions for fiscal policy that have big implications for the inflation outlook. For instance, the Treasury's forecasts for stamp duty and capital gains tax are presumably informed by views as to how house prices are likely to change. The Code should require the Treasury to share all of its key forecast assumptions with the MPC, regardless of whether or not it discloses them to the general public. This would not only increase the information available to the MPC but would enable the Treasury to have some unofficial external audit of its assumptions.

\subsection{Responsibility}

The Code for Fiscal Stability states (paragraph 6) that:

"The principle of responsibility means that the Government shall operate fiscal policy in a prudent way, and manage public assets, liabilities and fiscal risks with a view to ensuring that the fiscal position is sustainable over the long term."

\section{Caution in forecasting}

The Code requires the government to "operate fiscal policy in a prudent way" but provides no further guidance on how this is to be achieved. It would be unduly restrictive for the Code to mandate the degree of caution that is required for a "prudent" fiscal policy, since this is by definition dependent on the normative judgement of the

21 ibid, p.107 
government of the day and will also vary over time depending on whether the risks to the forecasts seem particularly large and/or asymmetric. However, in light of the present government's actions to ensure prudence, we think the Code should specify in more detail the appropriate way to incorporate caution into forecasts and what information the government should be required to publish about how prudent its projections are.

The present government complies with the requirement for prudence by producing its forecasts for receipts and spending on the basis of some cautious assumptions. Fiscal policy is then set so that this forecast projects a safety margin - ie, a greater current budget surplus than is required to meet the golden rule and a lower public sector net debt ratio than is required to meet the sustainable investment one. This approach builds in two 'layers' of caution - the cautious assumptions and the margin of safety. The benefit of this caution is that some level of adverse shock can be accommodated within the Government's fiscal objectives. However, it lacks clarity, which makes retrospective examination of fiscal policy and independent auditing of fiscal policy more difficult. For instance, if an expected safety margin fails to materialise, to what extent is this because the government did not aim for a large enough safety margin and to what extent is it because the cautious assumptions were not cautious enough? It is also unhelpful to independent forecasters to know that an assumption is 'cautious'. What really matters is how much of a difference using the cautious assumption makes to the forecasts.

A more helpful approach would be to publish a genuine central forecast, based on central assumptions, with a given, formally stated safety margin (such as, "Our forecast, based on central assumptions, is for a current budget surplus of $1 \%$ of national income five years ahead."). This would enable the public and independent forecasters to know exactly how much caution each forecast contained. A forecast based on central assumptions would also, one hopes, be more accurate than one based on cautious assumptions. While it may be politically appealing for the government to be able to announce each year that the fiscal position is stronger than it predicted a year ago, the aim should be to minimise forecast errors in either direction. If forecasts are repeatedly more pessimistic than outturns - as was the case for the year-ahead projections in the 1997, 1998, 1999 and 2000 Budgets - then their credibility could become undermined.

\section{The auditing of assumptions}

Although the auditing of assumptions is not covered by the 'responsibility' clause of the Code for Fiscal Stability but appears as a separate section ('Role of the National Audit Office', paragraph 26), the manner in which the key assumptions underlying fiscal projections are audited has major implications for the prudence of fiscal policy. In its present form, the Code states that, "The Treasury shall invite the National Audit Office (NAO) to audit any changes to the key assumptions and conventions" (our italics). In other words, the assumptions themselves do not have to be re-audited if they are unchanged, and the NAO only conducts audits at the Treasury's invitation. This is less demanding than the IMF 'Revised Code of Good Practices on Fiscal Transparency' paragraph on the independent scrutiny of fiscal information, which states, "Independent experts should be invited to assess fiscal forecasts, the macroeconomic forecasts on which they are based, and all underlying assumptions" (our italics). 
The present government lists several 'key assumptions' that underpin public finance projections in each Financial Statement and Budget Report (FSBR) and Pre-Budget Report. Each assumption is audited at least once every three years, so about one third of the assumptions have been recently audited at the time of each FSBR. For each audit, the Comptroller and Auditor General publishes a report in which he checks "both that the audited assumptions remain reasonable and cautious, and...[that] they were reasonable and cautious in the period since they were last audited". 22 It is worth noting that the present arrangements go beyond the requirements of the CFS by auditing assumptions regularly even if they have not changed.

However, they still have shortcomings. Asking an independent auditor if one's assumption is 'reasonable' is a less demanding test than asking him if it matches what his own central assumption would be. Presumably, any assumption that is not unreasonable would pass the former test, whereas only assumptions that are in line with the auditor's calculations would pass the latter. Also, the practice of selecting a list of key assumptions and auditing each assumption every three years opens two worrying theoretical possibilities. The first is that the non-audited assumptions could be 'fudged', undermining the reliability of fiscal projections. The second is that circumstances could change significantly in the three years between audits but the Treasury could fail to request a new audit of the affected assumptions until they are due for reconsideration. This would mean that public finance projections were made for up to three years on the basis of incorrect assumptions.

How could the Code be changed to address these shortcomings? First, rather than selecting "a number of key assumptions" for audit, the Treasury should be required to publish and present to the NAO a list of all assumptions used in fiscal projections (except those that have to be withheld due to reasons such as those discussed in the 'Transparency' section). To avoid the possibility of assumptions lapsing into inaccuracy, the NAO should be allowed to publish, if it chooses to, a brief update on each assumption every year. Given that the Treasury already has assumptions audited regularly even though they have not changed, this addition to the Code would only expand and improve an existing practice.

Finally, the aim of an audit should not be to get the NAO to 'sign off on the Treasury's assumptions or to make judgements as to how cautious they are. The NAO should indicate what it considers to be a reasonable range within which central assumptions should fall, with the emphasis being on whether or not the Treasury's assumptions fall with that (independently determined) range. Indeed, requiring the Treasury to publish all of its key central assumptions - and how it reached those assumptions - would enable all independent commentators to assess whether they consider those assumptions reasonable or not. Ideally, the Treasury would explain its key assumptions in the same way as it discussed its trend growth forecasts in November 1999 and April 2002.23 Rather than having one assumption and one assessment, the public should be able to

\footnotetext{
22 See, for example, paragraph 5 of National Audit Office (2003).

23 See http://www.hm-treasury.gov.uk/mediastore/otherfiles/ACF521.pdf and http://www.hm-
} treasury.gov.uk/documents/uk economy/fiscal policy/ukecon fisc trend.cfm. 
compare the Treasury's and the NAO's views and draw independent conclusions. In summary, although the existing system works relatively well for the assumptions that are published and audited, public disclosure of all key assumptions and methodologies and an NAO 'audit option' for all assumptions, at any time, would be considerable improvements.

\section{The timing of the economic cycle}

Although the Code for Fiscal Stability states explicitly that National Audit Office should be invited to audit any changes to the assumptions that underpin the fiscal projections, there is no requirement anywhere in the Code for the Treasury to submit its projections and assumptions about the timing of the economic cycle to any external, independent bodies. As well as being necessary for the calculation of the cyclically adjusted fiscal position, the timing of the economic cycle is particularly important when, as is the case presently, the fiscal rules are judged 'over the course of the cycle'. In particular, the precise dating of the cycle's start and end could, potentially, affect whether or not the golden rule is met.

The Treasury has provided, voluntarily, explanations of its methodology for calculating when the economy is 'on trend' and the trend rate of growth. In particular, HM Treasury (2002d) discusses in considerable detail how the Treasury identifies 'on-trend' points to date the start of cycles. However, the Treasury's method for dating the cycle is only one of several ways. Others include the use of a statistical filter (such as the Hodrick-Prescott and Kalman ones) or a production function. ${ }^{24}$ So there are alternative methods that may yield alternative answers. Moreover, the particular method that the Treasury uses - not a statistical technique to identify on-trend points but, instead, an (ultimately subjective) "broad assessment of the available information" - means that even among those who use the same method, the cycle could be dated differently. For instance, HM Treasury (2002d) discusses in Box 2.1 the evidence as to whether or not 2001Q3 was an on-trend point. Although the British Chambers of Commerce manufacturing and services capacity utilisation indicators were both above their estimated long-run levels in the third quarter of 2001, which could imply an above-trend economy, the average earnings indices in manufacturing and services fell at the end of 2001, suggesting that by the end of 2001 the economy had moved to below trend. The Treasury chose to decide that the economy was on trend in 2001Q3, but it is conceivable that another economic commentator could have dated the on-trend point as 2001Q4 instead.

Given the importance of the dating of the cycle and the fact that there are several alternative ways of doing so, the Code for Fiscal Stability ought to require the Treasury to publish the information that it currently volunteers about its methodology, trend growth assumptions and cycle dates. In addition, the Code should require an external body - perhaps the NAO - to audit regularly the Treasury's list of on-trend points and cycle dates. The external body could also assess the Treasury's analysis of the trend growth rate, because the dating of the economic cycle depends on when output crosses

\footnotetext{
24 The IMF and OECD both use production functions. The EC has estimated UK trend growth using both a production function and a Hodrick-Prescott filter. See HM Treasury (2002d) for details.
} 
the 'trend output' line, which in turn depends on the gradient of that line. The Treasury has already allowed the NAO to audit trend growth assumptions, including the 2002 Budget's change to the rate of growth used in fiscal projections from $2 \frac{1}{4} \%$ to $2 \frac{1}{2} \%{ }^{25}$ It is appropriate to have the comparable levels of external scrutiny of both short-term projections, trend growth in the economy, but also the assessments of when the economy was last thought to be operating at trend.

\section{Forecast errors and uncertainty}

The public and independent forecasters cannot assess whether or not the government is operating fiscal policy in a prudent way unless the government publishes information as to the accuracy of its past forecasts and the uncertainties surrounding its present forecasts. Although paragraph $21(\mathrm{~g})$ of the CFS requires the government to publish in its economic and fiscal projections "an indication of past forecast errors for aggregates", the Code should specify in greater detail what information is required and how that information ought to be presented. This would not only enhance the quality of information available, but would also improve public understanding of the nature of the uncertainty inherent in economic projections. ${ }^{26}$

The present system of publishing exact numbers for fiscal forecasts creates the impression that - unlike, for example, national income or inflation - fiscal aggregates such as Public Sector Net Borrowing (PSNB) or the current budget surplus can be predicted exactly even five years ahead. While it may be true to some extent that public service spending can be controlled, the reality is that large parts of public spending tend to vary in line with the state of the economy and other factors such as changes to demographics, household composition and health, none of which the government can predict with certainty. Similarly, with respect to tax receipts, although the government can predict the level of receipts that it expects a given tax system in given economic conditions to deliver, there is no way of knowing precisely what the tax take will be until it has been received.

The fact that the Treasury publishes information on its past forecasting errors goes some way to dispelling the impression of precise forecasting. But, other than stating that "forecasts are inevitably subject to wide margins of uncertainty" and indicating that "Over the past ten years, the average absolute difference between year-ahead forecasts of net borrowing and subsequent outturns has been around 1 per cent of GDP", 27 the Financial Statement and Budget Report contains little data on past errors. Each of the 2002 and 2003 Pre-Budget Reports was accompanied by an 'End of year fiscal report', which included some useful analysis of the Treasury's historical forecasting performance. Neither report contained data series of actual forecasting errors (i.e. adjusted for

\footnotetext{
${ }^{25}$ See National Audit Office (2002).

${ }^{26}$ Similarly, it would be desirable for independent forecasters to disclose their forecasting errors. Appendix A of each IFS Green Budget discusses the accuracy of the previous Green Budget's short-term forecasts, while the working paper by Basu, Emmerson and Frayne (2003) discusses the accuracy of IFS's medium-term corporation tax forecasts in more detail.

${ }^{27}$ From HM Treasury (2004), paragraph C20, p.247
} 
subsequent policy announcements), although these could, in theory, be calculated using past Budgets. More importantly, neither report used the information on past forecasting errors to indicate what this might imply about the degree of uncertainty surrounding current forecasts, or to indicate the probability distribution within which these forecasts should be placed. While the publication of information on forecasting errors in the End of year fiscal reports is a major improvement, there is much more in this area that can and should be done.

The Code for Fiscal Stability should require the Treasury to publish once a year a data series, going back at least a decade, of forecasting errors for the main fiscal aggregates (including, at the very least, PSNB, public sector net debt, the current budget balance, current receipts, current spending and public sector net investment). The data series should compare the initial forecast - adjusted for subsequent policy changes - with the final outturn. ${ }^{28}$ The Treasury should also be required to produce regular summary statistics about the size and variability of its forecasting errors, as it has been doing since the 2002 End of year fiscal report. Table 3.1 shows the summary statistics for forecasts of PSNB made one, two three and four years ahead, in publications from the March 1977 FSBR onwards. The forecasts have not been corrected for subsequent policy changes, so they are likely to understate the true errors. This is because if a forecast looked unlikely to be met, the government might well make policy adjustments to improve the chances of meeting it.

The table shows that forecasts made one and two years ahead have been reasonably unbiased, with a small positive average error. The average absolute error is much larger, at $1.0 \%$ of national income for one-year-ahead forecasts and almost 3.0\% for four-yearahead ones. This reflects the inherent difficulty of forecasting PSNB. The variation in the forecast errors has also, unsurprisingly, increased as the time interval between the year in which the forecast was made and the outturn has widened. Giles and Hall (1998) produced a comparison of IFS and HM Treasury forecasts of the Public Sector Borrowing Requirement (PSBR, an aggregate that is now known as the Public Sector Net Cash Requirement and is the cash equivalent of PSNB), with similar summary statistics to those in Table 3.1.

Table 3.1. Summary of forecasting errors for Public Sector Net Borrowing, 1977-78 to 2002-03

\begin{tabular}{lcccc}
\hline in \% GDP: & 1 year ahead & 2 years ahead & 3 years ahead & 4 years ahead \\
\hline Average error & $0.05(£ 0.6 \mathrm{bn})$ & $0.05(£ 0.6 \mathrm{bn})$ & $-0.58(-£ 6.5 \mathrm{bn})$ & $-1.10(-£ 12.3 \mathrm{bn})$ \\
Average absolute error & $1.03(£ 11.5 \mathrm{bn})$ & $1.65(£ 18.4 \mathrm{bn})$ & $2.22(£ 24.8 \mathrm{bn})$ & $2.95(£ 32.9 \mathrm{bn})$ \\
Standard deviation of errors & 1.26 & 1.98 & 2.82 & 3.62 \\
\hline
\end{tabular}

Notes: Statistics on the 1 year ahead errors are constructed using all years' outturns from 1977-78 to 2002-03; statistics on the 2 year ahead errors use outturns from 1981-82 to 200203; statistics on the 3 year ahead errors use outturns from 1982-83 to 2002-03 except the years 1996-97 to 1999-2000; and statistics on the 4 year ahead errors use outturns from 1983-84 to 2002-03 except the years $1984-85$ to $1986-87$ and $1997-98$ to $2000-01$. Amounts in £bn are calculated using 2003-04 national income of $£ 1,115 \mathrm{bn}$. Source: Authors' calculations, from data contained in HM Treasury (2003b).

${ }^{28}$ The Congressional Budget Office (2003) performs similar analysis for its own projections of US borrowing. 
Having produced these statistics about the forecasting errors and summarised their distribution, the Treasury should then be required to use the distribution of past forecasting errors to indicate the probability distribution of errors and to quantify the uncertainty surrounding its current set of fiscal forecasts. In other words, much as the Bank of England's Quarterly Reports publish 'fan charts' for their inflation forecasts ${ }^{29}$, the Treasury should produce fan charts for projections of aggregates like PSNB. By making certain assumptions about the distribution of forecast errors, it is possible to construct confidence intervals around predictions. Figure 3.1 illustrates what such a chart might look like for the PSNB forecasts contained in Budget 2004. The pair of dark blue bands around the 'Central' estimate contain within them $20 \%$ of the probability distribution, the pair of purple-blue bands contain $40 \%$, and so on. The probability distribution is based on the assumption that these errors follow a normal distribution ${ }^{30}$ with a mean error of zero (ie, the forecasts do not have an overall positive or negative bias). The standard deviation of that distribution is taken from Table 3.1. We emphasise that the fan charts do not show the 'true' probability distribution of future PSNB, as they assume unchanged policies. In reality, if the government were aiming to achieve a certain level of PSNB by the end of the forecasting period and seemed unlikely to do so, the Treasury could take corrective action. It is also the case that the standard errors used are likely to be underestimates of the true standard errors, as they are not adjusted for subsequent policy changes. This suggests that, if anything, the fan would be more spread than that presented in Figure 3.1.

Figure 3.1. An illustrative fan chart for the Treasury's forecasts of Public Sector Net Borrowing in the medium term

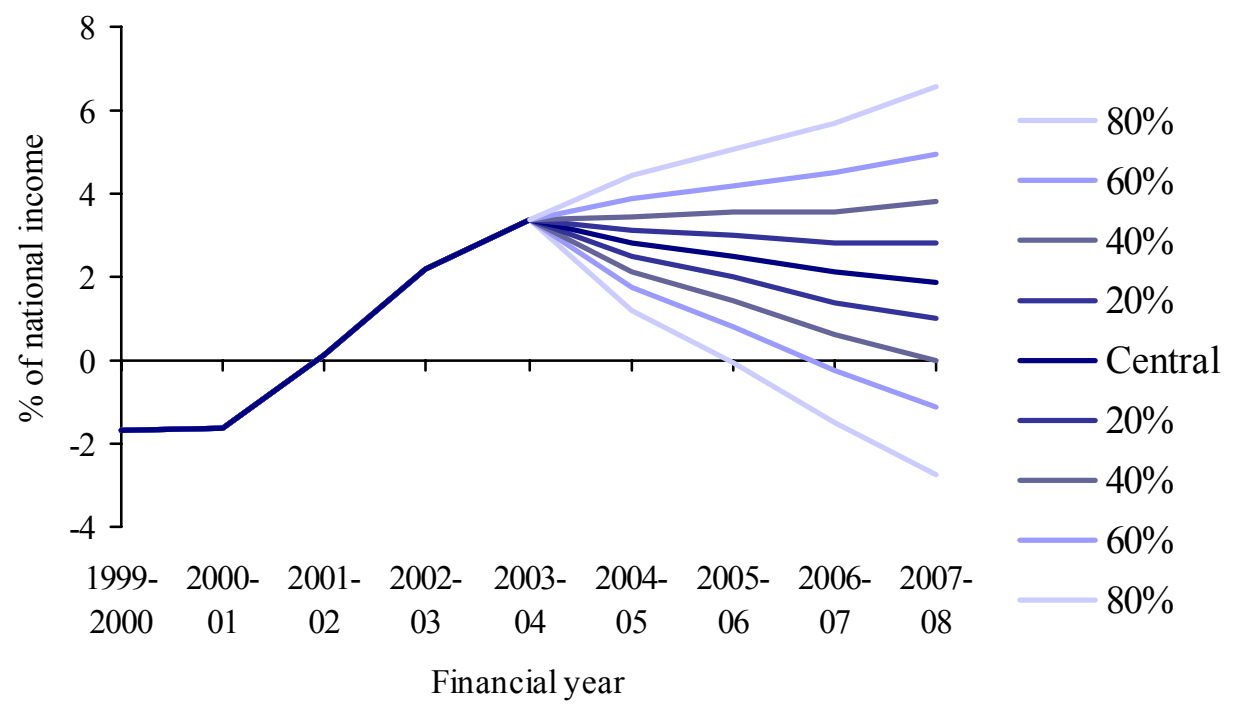

\footnotetext{
${ }^{29}$ See, for example Bank of England (2004).

30 The ratio of average absolute errors to standard deviation of errors is close to $0.8: 1$, which is what it would be if the errors were normally distributed. See, for example, http://www.uvm.edu/ dhowell/EBS/Average deviation.pdf for further details.
} 
Source: Central projections are taken from HM Treasury (2004); Standard errors authors' calculations, from data contained in HM Treasury (2003b).

The figure shows the extent to which forecasts should not be regarded as precise indications of future outturns. While PSNB is expected to be $2.8 \%$ of national income this year (2004-05), there is actually only a 40\% chance that the outturn will be between $2.1 \%$ and $3.5 \%$ of national income. The likelihood of PSNB falling between $1.2 \%$ and $4.4 \%$ of national income is $80 \%$. So there is a $20 \%$ chance that PSNB will fall outside even this wide range. By $2007-08$, the $80 \%$ confidence interval ranges from $-2.7 \%$ to $+6.5 \%$ of national income, relative to a central prediction of $1.9 \%$ of national income, with a $10 \%$ chance that PSNB will exceed $6.5 \%$ of national income and a $10 \%$ chance that it will be less than $-2.7 \%$ of national income.

Presenting information on forecasts in this format would have several advantages. Haldane (2000) comments that an advantage of the Bank of England's fan charts is that "a quantified distribution allows policy to be exercised in an explicitly probabilistic fashion". Translating this to the planning of the public finances, rather than making statements such as, "We expect to meet our fiscal rule with $f \mathrm{X}$ billion, or Y per cent of national income, to spare", the Chancellor would be able to say, "The fact that we have an $\mathrm{fX}$ billion expected surplus means that there is only a $\mathrm{Z}$ per cent chance that our fiscal rule will not be met." Such a statement would make it clear that no reasonable safety margin or expected surplus could ever guarantee that a fiscal rule will be met. The best one can do is decide how large a probability of breaking the rule is tolerable and plan accordingly. Rather than focusing on whether the Chancellor was 'right' or 'wrong' - whether he or she has 'hit' or 'missed' a fiscal rule - it would be more productive to analyse where, within the probability distribution, the Chancellor chose to aim. Also, by quantifying explicitly the likely range within which fiscal aggregates will fall, a fan chart presentation (or some other format that incorporated confidence intervals) would increase stability and credibility by underlining that it is perfectly normal for outturns not to be exactly in line with forecasts. It would also aid independent assessment of whether the degree of caution in the forward looking projections had changed over time as the fan charts would allow an easy calculation of whether the likelihood that borrowing will exceed a given amount in 4 years time is now greater or smaller than it was a year ago.

Our suggestion of presenting information on forecast errors in the form of fan charts is not an original one. Indeed, the Treasury Committee of the House of Commons stated in its report on the November 2002 Pre-Budget Report, ${ }^{31}$

"From the forthcoming Budget onwards, we recommend that the Treasury should present the projections of the public sector net borrowing, the current budget and the cyclically-adjusted current budget in the style of a "fan chart", similar in style to those published by the MPC and the US Congressional Budget Office. The fan charts should show the projection of the most likely outcome of the public finances, and the range of other possible outcomes up to a ninety per cent level of confidence. The Treasury should also 
publish the numerical parameters of the fan charts (including the mean, mode and median for each financial year) as an annex to the Budget and the PBR. We believe the adoption of fan charts would greatly enhance the presentation and transparency of the public finance projections."

However, the government did not act on the Committee's recommendation. In some respects this is surprising, as using fan charts would show the extent to which uncertainties increase as the time horizon extends. This might, in turn, demonstrate why a safety margin is required in forecasts. In late 1999, some independent commentators suggested that Gordon Brown was forecasting current budget surpluses to finance a 'war chest' for the 2001 general election. ${ }^{32}$ The reality was that these surpluses were necessary if the Chancellor was to have a reasonable likelihood of meeting his golden rule by March 2006, as Figure 3.2, below, makes clear.

In addition, where forecast errors for one, two and subsequent years ahead are available, it would be informative to know the extent to which forecast errors of forecasts made $\mathrm{X}$ years ahead are correlated with those of forecasts made $\mathrm{Y}$ years ahead. In other words, if the forecast made in a Budget for next year turns out to be overoptimistic, is the forecast made in the same Budget for the year after next also likely to be overoptimistic? Table 3.2 shows this information for the same data used to construct Table 3.1. According to the table, forecasting errors for subsequent years that were made in the same publication tend to be highly correlated. This is true even for years that are relatively far away. For example, there is a correlation coefficient of 0.70 between the forecast made for PSNB two years ahead and that made for PSNB four years ahead.

Table 3.2. Correlations between forecasting errors for Public Sector Net Borrowing

\begin{tabular}{c|cccc}
\hline Years ahead: & 1 & 2 & 3 & 4 \\
\hline 1 & 1.00 & & & \\
2 & 0.76 & 1.00 & & \\
3 & 0.53 & 0.89 & 1.00 & 1.00 \\
4 & 0.38 & 0.70 & 0.90 & \\
\hline
\end{tabular}

Notes: Statistics on the 1 year ahead errors are constructed using all years' outturns from 1977-78 to 2002-03; statistics on the 2 year ahead errors use outturns from 1981-82 to 200203; statistics on the 3 year ahead errors use outturns from 1982-83 to 2002-03 except the years 1996-97 to 1999-2000; and statistics on the 4 year ahead errors use outturns from 1983-84 to 2002-03 except the years $1984-85$ to $1986-87$ and $1997-98$ to $2000-01$. Source: As for Table 3.1.

Having information on the distribution of, and correlation between, errors made on subsequent years' forecasts also enables one to see how the probability of hitting a target for cumulative fiscal measures (ie, stocks that depend on several previous years' outturns) changes over time. Figure 3.2 uses the data in Tables 3.1 and 3.2 and, under the assumption that the standard deviation of errors in projections of the current budget

${ }^{32}$ See, for example, http://news.bbc.co.uk/1/hi/business/the economy/526193.stm. 
surplus is the same as that for Public Sector Net Borrowing ${ }^{33}$, shows how the probability that the present Chancellor will meet his 'golden rule' has changed in the past two years.

The horizontal axis of Figure 3.2 shows the expected cumulative current budget surplus over the entire economic cycle as a share of national income. This is the sum of each year's actual or expected current budget surplus as a share of national income for the seven years (1999-2000 to 2005-06) of the present economic cycle. The Treasury deems the golden rule to be met if this cumulative current budget surplus is at least zero. The vertical axis then gives the probability that the golden rule will actually be met. In other words, given the number of years of the economic cycle remaining and the expected size of the cumulative surplus, the axis shows the likelihood that the final cumulative surplus to materialise will actually be at least zero. For example, because we assume that the forecast errors are not biased in either direction and that the distribution of errors is symmetrical, a forecast cumulative surplus of exactly zero means a probability of meeting the golden rule of exactly 0.5 : underachievement is as likely as overachievement. This is the case regardless of the number of years remaining when the $0 \%$ cumulative surplus forecast is made. We also exclude the possibility that the Chancellor will choose to implement new measures to increase the cumulative surplus in the event of disappointing outturns. So the probabilities shown on the chart really refer to the likelihood of meeting the golden rule without requiring further tax increases or spending cuts.

Figure 3.2. How the probability of meeting the golden rule varies with the expected cumulative current budget surplus and the number of years remaining

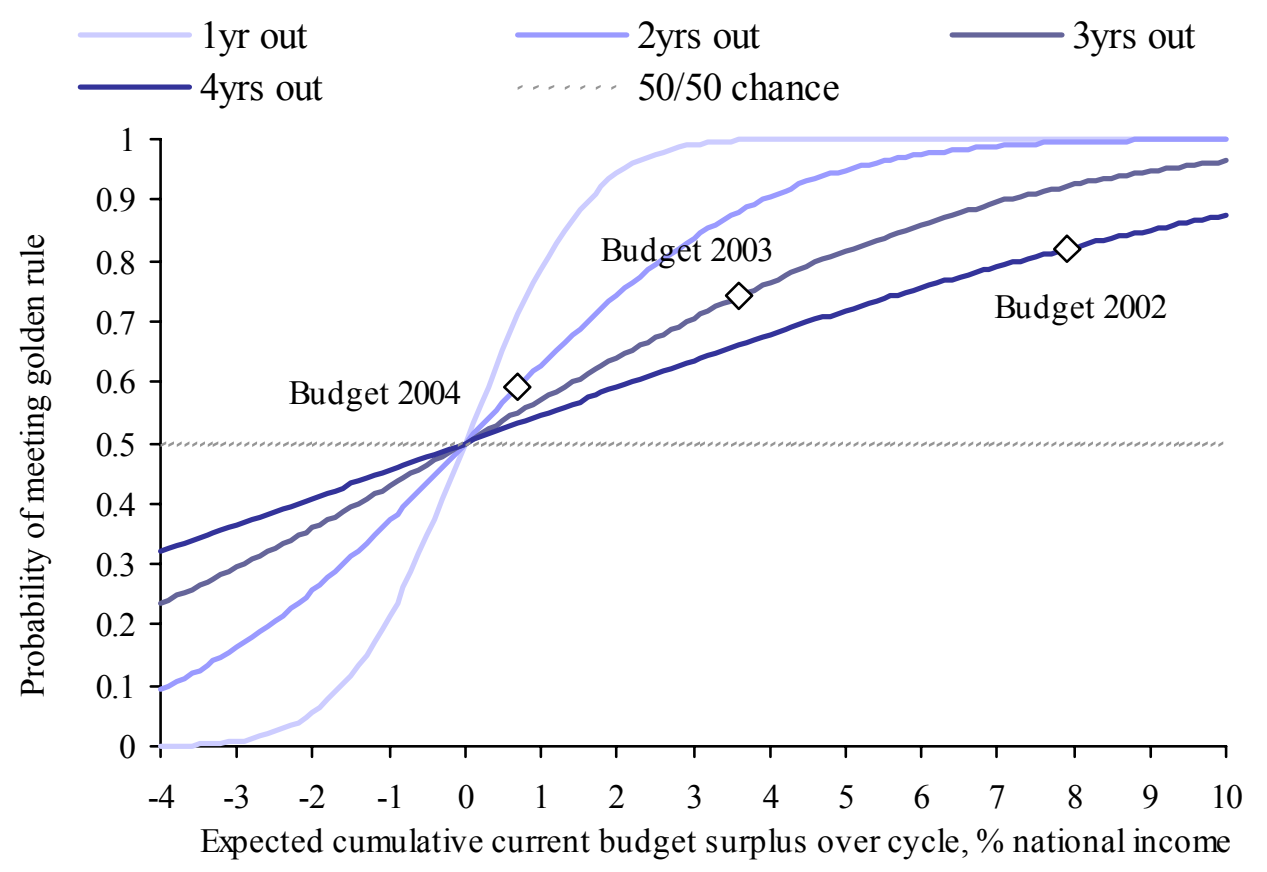

${ }^{33}$ See Appendix A for more details of what this would imply for the errors in forecasting Public Sector Net Investment. 
Source: Central estimates for the current budget surplus from HM Treasury (2002), HM Treasury (2003a) and HM Treasury (2004); standard errors and correlations in errors over time from authors' calculations using from data contained in HM Treasury (2003b).

The extent to which an extra year of uncertainty causes the probability distribution to be spread more widely is striking. With four years of outturns to come, the April 2002 FSBR prediction of a substantial cumulative surplus of $7.9 \%$ of national income by March 2006 meant that there was an $82 \%$ probability of the actual cumulative surplus being at least $0 \%$ by March 2006. To achieve the same probability a year later would have required an expected cumulative surplus of only $5.1 \%$ of national income. By March 2004, a margin of just $2.8 \%$ of national income would be required for an $80 \%$ likelihood - about one third of the $8 \%$ required in 2002. To raise the probability of hitting a cumulative target several years ahead requires a significant increase in the margin of safety. This shows that the significant reduction in the expected cumulative surplus on the current budget between Budget 2002 and Budget 2003 did not imply a large increase in the likelihood that the golden rule would be missed.

Conversely, even small changes in the safety margin can have big effects on the probability when there is only one year remaining: increasing the expected cumulative surplus from $0.6 \%$ to $0.8 \%$ raises the probability of meeting the golden rule from about $2 / 3$ to $3 / 4$. So a small amount of bad luck in the closing years of an economic cycle could have big adverse effects on the chances of meeting a cumulative fiscal rule. For example, the latest prediction in Budget 2004 is for a cumulative surplus of $0.7 \%$ of national income, which translates into a likelihood of meeting the golden rule of just below $60 \%$. The new cumulative surplus figure is 2.9 percentage points less than the $3.6 \%$ surplus that was expected in Budget 2003, when the expected probability of meeting the rule was $74 \%$. So a $2.9 \%$ reduction in the surplus 'cost' 15 percentage points of probability. A deterioration of the same size between 2002 and 2003 - from an expected cumulative surplus of $7.9 \%$ to one of $5.0 \%$ - would have only caused the probability of meeting the golden rule to drop from $82 \%$ to $81.6 \%$. It is clear from Figure 3.2 that, unlike the deterioration in the forecasts made between Budget 2002 and Budget 2003, the deterioration from Budget 2003 and Budget 2004 has led to a substantial reduction in the probability that the golden rule will be met without tax increases or spending cuts.

Clearly it is not appropriate for the Code to specify the exact format in which forecast risks and historical errors can be presented. But there should definitely be a requirement not only to publish data on past errors but to quantify future uncertainty. Part of the aim of this subsection was to show that publishing uncertainties has the potential to change the way in which forecasts, targets and rules are interpreted from an overemphasis on point estimates and hitting targets to an awareness that coming within a few percentage points of a target does not constitute a fiscal policy failure.

\subsection{Fairness}

The Code for Fiscal Stability states (paragraph 7) that: 
"The principle of fairness means that, so far as reasonably practical, the Government shall seek to operate fiscal policy in a way that takes into account the financial effects on future generations, as well as its distributional impact on the current population."

It is right that the Government should consider the financial effects of fiscal policy on both the current and future generations. As with the issues discussed above in the transparency section whenever possible this analysis should be published.

\section{The current generation}

For the current population both the distributional impact and also the effects on individuals' incentives (for example to work and to save) are of particular policy interest.

In practice, the Government has often chosen to publish information on both of these. The 2002 Budget, which finalised the details of both the new tax credits for families with and without children and also the Pension Credit, is a good example. The effects of both of these policies across the income distribution were published in the Budget documentation. ${ }^{34}$ In terms of incentives Budget 2002 also published the impact of the reforms on the numbers of families facing high marginal deduction rates above 60 percent. ${ }^{35}$ This practice is very welcome, although some of the analysis could have been helpfully extended. For example it would have been preferable for the analysis of marginal deduction rates to be extended to include all marginal rates. ${ }^{36}$

There is no reason why the Code for Fiscal Stability should not contain an explicit requirement that, where significant and possible, the distributional impact on the current population of new measures should be made publicly available. Similarly estimates of the impact on marginal deduction rates across the whole population should also be provided. The fact that the Government has often chosen to exceed the requirements of the existing Code shows that publishing such information is often feasible. It is also desirable that indicative information be made available as early as possible in the consultation process rather than simply being provided when all of the details of the policy have been finalised. When the government introduced the Working Families' Tax Credit in the 1998 Budget, for example, the Treasury published some detailed supplementary information, including a table showing the effect of the Budget on marginal tax rates and the distribution of income. It would have been preferable for this analysis to have preceded, rather than accompanied, the Budget. ${ }^{37}$

\footnotetext{
34 See Chart 5.2, Page 89 and Chart 5.3 page 95 of HM Treasury (2002).

35 See Table 4.4, Page 79 of HM Treasury (2002).

36 This analysis can be, and occasionally is, produced by the Government. See, for example, an extension of Table 4.4 of Budget 2002 to families facing marginal deduction rates over 40 percent in Hansard Commons Written Answers, 1/05/02, Section 'Budget Red Book', Column 882W. http://www.hm-treasury.gov.uk/media//6A702/taylor.pdf $\quad$ and http://www.hmtreasury.gov.uk/media/1D $41 \mathrm{C} /$ wftc.pdf.
} 
For many policies, the immediate effects on the distribution of income and the numbers of individuals facing different marginal deduction rates will give a reasonable indication of the effect on future generations. In some cases - for example, new pension policies that often will not reach maturity for more than half a century - further analysis would be desirable. Again there are examples of when the Government has chosen to provide such information. The Department for Work and Pensions has chosen to publish its long-run projections of the cost of the Pension Credit, introduced in October 2003, under different methods of indexation and also projections of how the number of individuals eligible might change over time. ${ }^{38}$ This information is very important when assessing the sustainability of the UK pension arrangements. The Code for Fiscal Stability should also explicitly state that where the long-term implications of a policy are estimated to be substantially different to the short-term impact then the former should also be published. As these implications will often depend on the indexation decisions made by future governments, different scenarios should be considered. For example, it will usually be sensible to provide projections both under the assumption that system parameters are indexed in line with prices and under the alternative assumption that they are indexed in line with earnings. This practice is already carried out in the Government Actuary's Department's quinquennial reviews of the National Insurance Fund. ${ }^{39}$ As well as the paragraph on fairness, the Code for Fiscal Stability contains more specific requirements regarding the publication of information about the fairness of fiscal policy across generations. Paragraph 19, for example, requires the government to include in its Economic and Fiscal Strategy Reports "illustrative projections of the outlook for the key fiscal aggregates for a period not less than 10 years into the future, based on a range of plausible assumptions, so as to shed light on the inter-generational impact and sustainability of fiscal policy". The government fulfils this requirement by producing 'Illustrative long-term fiscal projections' in Annex A of each Budget. ${ }^{40}$ The government has also published additional long-term fiscal analyses, such as the 'Long-term public finance report: fiscal sustainability with an ageing population' that accompanied the 2003 Pre-Budget Report. ${ }^{41}$ This report included a discussion of generational accounts as a means of assessing fairness. While such publications are welcome, the Code ought to oblige the government not only to produce illustrative projections of inter-generational fairness but also to show how these are affected by potential and actual new reforms.

\subsection{Efficiency}

The Code for Fiscal Stability states (paragraph 8) that:

\footnotetext{
${ }^{38}$ Projections of numbers eligible can be found in table 8, annex B of Department for Work and Pensions (2002). The DWP's long-term projections of benefit expenditure can be found at http://www.dwp.gov.uk/asd/asd4/long term.asp.

${ }^{39}$ For the most recent example see Government Actuary's Department (2003).

${ }^{40}$ See http://www.hm-treasury.gov.uk/media//CED06/bud04 annexa 241.pdf for the most recent Annex A (2004).

${ }^{41}$ See http://www.hm-treasury.gov.uk/media//555E2/longterm fiscal_1to6 436.pdf
} 
"The principle of efficiency means that the Government shall seek, to ensure that it uses resources in ways that give value for money, that public assets are put to the best possible use and that surplus assets are disposed of. The Government shall also have regard to economic efficiency and compliance costs when forming taxation policy."

Efficiency refers to the quality and quantity of output obtained for a certain amount of input. It is difficult to measure even the quantity of some of the public sector's outputs let alone the quality, which makes the government's efficiency hard to gauge. ${ }^{42}$ It also seems highly unlikely that a government would not be striving to use its resources efficiently. Furthermore making efficient use of public resources is also a prerequisite for implementing the other principles of the Code for Fiscal Stability successfully: a government that makes inefficient use of public assets and tax receipts would, for instance, be unlikely to fulfil the requirements of the 'Responsibility' section. So why does the Code contain a section referring to a desideratum that is difficult to measure and that the government probably wants to achieve anyway?

The main reason for including efficiency in the Code is that although a government is unlikely to want to waste large sums of public money or to run projects inefficiently, there may be instances where it might stand to gain politically from sacrifices of efficiency. For instance, if a government wants to achieve a certain policy objective, it may be easier to regulate and leave the financial costs of complying with the regulation to employers or individuals than to finance the objective out of taxation, even though the former may end up costing the economy more than the latter. If a government has a fiscal rule limiting the size of public sector net debt and the debt limit is approaching, ministers may be tempted to use 'off-balance sheet' methods of financing spending projects that require large capital investments. Otherwise, they risk the embarrassment of breaking the fiscal rule.

It is therefore important that the Code requires the government to disclose (i) the criteria it uses when evaluating policy objectives and spending proposals; and (ii) the data it uses to judge whether or not the criteria are met. However, the Code correctly requires that efficiency be only a consideration rather than a definite requirement as it can be in conflict with other requirements of the Code (such as fairness) or other political principles the electorate may wish the government to respect. ${ }^{43}$

\section{Evaluating the best way to achieve policy ends}

The direct cost of spending programmes to the exchequer is covered in our discussion of the 'Transparency' section of the Code. With many policies, there will be a choice over the extent to which the costs fall directly on the exchequer (for example, through public service provision) and the extent to which greater costs are imposed on third parties such as employers (for example, through greater regulation). With respect to the latter, the nature of the costs will, in many cases, make them harder to quantify with a high degree of accuracy. However, for the efficiency criteria set out in the Code for

\footnotetext{
42 A detailed discussion of the issues can be found in Atkinson (2004).

${ }^{43}$ For example in determining taxation policy, there will often be a trade-off between efficiency and equity.
} 
Fiscal Stability to be met it is important that as much analysis as possible is published by the government. The government's current practice is to publish Regulatory Impact Assessments (RIAs).44 In 1998 the Prime Minister announced that no proposal for regulation that has an impact on business, charities or voluntary bodies, should be considered by ministers without an RIA being carried out. It seems appropriate that this practice should be formalised by the Code.

\section{Evaluating the relative merits of Government programmes}

To fulfil the definition of efficiency set out in the Code for Fiscal Stability, the government needs to compute carefully and compare the costs and benefits of different policies (both pre-existing and proposed). This will help to ensure that bad policies are phased out and that good policies are retained and potentially extended. Although there are other ways of carrying out such evaluations, with many new policies it will be possible to carry out pilots. ${ }^{45}$ Pilots enable the effects of a policy to be assessed with greater robustness. They can also reduce the cost to the taxpayer of introducing policies that turn out to be less effective than was expected: it is preferable to incur costs for a small-scale trial than nationwide. The government has used pilots in many areas to find the best way to implement a policy, and in some of these it has also been gathering evidence on the policies' effectiveness.

It will not always be possible or practical to pilot new policies. In some instances, the costs of pilots will be out of all proportion to the value of the information gained: a $£^{2} \mathrm{~m}$ painstaking pilot of a $£ 25 \mathrm{~m}$ project may reveal little more than a $£_{1}^{1 / 2}$ m theoretical simulation of the policy's likely effects. In other instances, the nature and/or timescale of the policy may render pilots inappropriate: randomly varying business subsidies by area or attempting to pilot Child Trust Fund accounts lasting 18 years are two examples. But the Code should state formally that all new policies should be subject to as comprehensive assessment of their likely costs and benefits as is possible, and that the judicious use of pilots, where practicable, should be part of that assessment.

\section{Evaluating the financing of government programmes}

In addition to deciding whether or not a programme is to go ahead, the government also needs to decide how the project should be financed and delivered. Projects that involve an initial capital outlay can either be conducted under traditional public sector financing arrangements or alternatively the Government can engage in a Public Private Partnerships (PPPs) where the private sector is also involved in the financing of the project. ${ }^{46}$ This assessment will require an assessment of the expected returns and risks over time. The accounting protocols are documented by the Treasury it its Technical Note 1,47 which also provides information on the extent to which PFI investments

\footnotetext{
44 The Inland Revenue website contains a useful list of both Partial RIAs and Full RIAs http://www.inlandrevenue.gov.uk/ria/.

${ }^{45}$ See Emmerson, McNally and Meghir (2004) for a discussion relating to UK education initiatives.

${ }^{46}$ For a discussion see, for example, section 3.2 of Dilnot, et al (2002).

47 Available at http://www.hm-treasury.gov.uk/media/8E294/PPP TTF Technote1.pdf
} 
should count as being on the public sectors balance sheet. A recent paper by the International Monetary Fund described the UK's decisions about how much risk a PPP contract contains and the extent to which that risk is transferred from the public to the private sectors as "a professional judgement based on all relevant factors". ${ }^{4}$

There is also evidence that by disclosing the criteria on which it bases its decision about how a public investment project should be financed, the government has benefited from advice from independent commentators on how those criteria could be improved. Prior to 2003 , the government used to decide whether to finance projects traditionally or with PFI by using a discount rate of $6 \%$ to compare the alternatives. Commentators argued that using such a high discount rate biased the assessment in favour of PFI. In the 2003 Treasury 'Green Book' (the guide publication on 'Appraisal and Evaluation in Central Government'), the discount rate was changed to $3.5 \%$ and a new 'optimism bias' was included in the calculation to take account of the historical tendency of potential delays and cost overruns. Had the government not publicised its assessment criteria in the 'Green Book', this methodological change might not have occurred. The current disclosure of data about the criteria for assessing PPPs and PFI contracts is generally laudable, and the Code should require such data to be made available. This would go further than the current, general requirement for the government to include in its economic reports "any other statements as are necessary to reflect fairly the projected financial performance of the Government" (paragraph 20(f)).

\section{The Code for Fiscal Stability and the choice of fiscal rules}

\section{What the principles imply about fiscal rules}

This paper is about the Code for Fiscal Stability, not the particular operating rules and system that are currently in use. So the aim is not to discuss how well the two rules that the present Chancellor uses to guide the conduct of fiscal policy are working and how their design could be improved. ${ }^{49}$ However, Section 3 discussed the theoretical issues that the Code's five principles raised with regard to the design and operation of fiscal rules, assuming that a government chooses to use rules (which the Code does not oblige it to do). This subsection considers what the government's choices of fiscal rule reveal about its opinions and priorities in respect to the theoretical issues.

The implications of Section 3 for the making of fiscal rules can be summarised as follows:

- Stability depends in part upon the predictability of the government's actions. So any fiscal rules should be assessed using a method that is clearly announced in advance and accompanied by a clearly articulated 'fiscal reaction function' explaining how the government would respond to failures to meet the rules.

\footnotetext{
${ }^{48}$ Source: IMF (2004), p.21.

${ }^{49}$ For information about how the specific rules are working, see Robinson (1998), Buiter (2001) and Emmerson, Frayne and Love (2004).
} 
- But specifying an intended reaction function does not mean that this function must always, without exception, be followed. If the government has a fiscal rule and chooses not to follow its preannounced response to a failure to meet that rule, it should offer some explanation for this departure. The CFS currently allows this to happen.

- As well as being clearly understood, it is important that the response function associated with any fiscal rule should be designed with the monetary policy reaction function in mind. This would suggest that fiscal reaction functions that might require abrupt policy tightenings in response to disappointing outturns should be avoided.

- Fiscal rules should be formulated in light of the large uncertainties inherent in forecasts of public finances aggregates and the distribution of those uncertainties. It is misleading to imply that just because a surplus is expected, a fiscal rule will be met when the reality is that no reasonable safety margin can possibly guarantee that it will be met without any future policy changes.

- Because errors of forecasts for different years made in the same publication have tended to be correlated with each other, fiscal rules regarding cumulative targets require particularly large safety margins if they are to be expected to be met (eg, if the likelihood of meeting the rule is to be greater than $75 \%$ ) several years ahead. But as the number of years to go until the end of the period covered by the rule decreases, the required safety margin to expect to meet the rule declines considerably.

In addition to the implications of the principles, there are other general points that can be made about different types of fiscal rule.

\section{Prospective versus retrospective rules}

A rule that focuses on past performance can only be judged to have been definitely hit or missed in retrospect. A rule that focuses on prospective performance can be judged on the basis of forecasts. Each kind of rule has different drawbacks associated with it, which is why, despite our preference on balance for a forward-looking interpretation of the present government's 'golden rule', we do not consider it appropriate for a bias towards one type of fiscal rule to be included in the Code.

With a retrospective rule, one can pinpoint when action has to be taken by if the rule is in danger of being breached. If a certain fiscal aggregate must reach a certain minimum level over the course of an economic cycle, every year, or every decade, then any inadequate performance must be compensated for by the end of the relevant period. (The only exception is if the disappointment occurs in the last year, although the government could always seek to compensate for this in the first year of the next relevant rule-meeting period.) By contrast, as was discussed in the 'Stability' part of Section 3, a prospective rule creates uncertainty because even if forecasts show that the rule is likely to be broken at a certain point in the future, the rule has not yet been 'missed' and there is no firm deadline by which corrective action must be taken. Also, the effectiveness of prospective rules depends on the credibility of the forecasts by which they are assessed. If the forecasts have been relatively inaccurate in the past, then 
knowing that the rule is expected to be met several years ahead, on the latest forecasts, is unlikely to anchor the public's expectations or improve their confidence in the future path of whatever fiscal aggregate the rule is targeting. Both of these factors suggest that, insofar as rules derive credibility from having a 'track record' of actual - not just predicted - achievement, it is easier to acquire such a track record with retrospective rules.

However, because prospective rules can be structured to avoid sharp deadlines, any corrective action that is required can be implemented smoothly over a number of years. By contrast, if - for example - a fiscal rule has to be met over a three-year period and the rule is set to be broken based on the first two years' performance, then abrupt policy changes can be required during the third year. Such abrupt changes, even if they are expected by the public (who know that the three-year deadline is approaching), are unlikely to enhance macroeconomic stability. In particular, increasing taxation or cutting public spending by a large amount just to achieve a rule by the end of a period and then promptly reversing the fiscal tightening would probably be undesirable. Of course, there may be macroeconomic reasons to tighten fiscal policy suddenly, but equally if the macroeconomic climate required a fiscal loosening then a fiscal tightening purely to achieve a fiscal rule in the short term would exacerbate the economy's problems. The fact that retrospective rules can require corrective action to be taken at relatively short notice also makes a retrospective rule more likely than a prospective one to trigger a monetary policy reaction that might have destabilising effects. This is one of the reasons why elsewhere we have suggested changing the interpretation of the present 'golden rule' from a retrospective to a prospective one. The Chancellor currently judges the golden rule on the basis of the average current budget surplus over the economic cycle. Our preferred alternative in this particular instance is for him to use a forward-looking interpretation, such as aiming to achieve a current budget surplus by the end of the forecasting period. ${ }^{50}$ The size of the surplus could be specified as, for example, $0.7 \%$ of national income - an amount that would be in keeping with the Treasury's own projections from previous Budgets.

The tradeoff between prospective and retrospective fiscal rules can therefore be summarised, crudely, as one between smoother policy adjustment and clearer verifiability - which could, in turn, mean greater credibility.

\section{'Hard' rules versus broader ones}

As well as choosing whether to interpret its fiscal rules in a prospective or retrospective way, the government also chooses whether to have 'hard' rules, which quantify exactly how big a surplus must be, how low a debt level must be, etc, or softer ones that indicate a central target within an acceptable range.

A 'hard' rule, like a retrospective rule, has the advantage of being easily understandable and verifiable, and may also be perceived by the public as 'stricter' and more demanding than a rule allowing a fiscal outturn to be anywhere within a band. However, the fact that

\footnotetext{
${ }^{50}$ See Chapter 2, pp.8-27, of Chote et al (2004) for a summary.
} 
there are large uncertainties surrounding fiscal outturns in future years means that to expect to meet a 'hard' fiscal rule, the government must build up a safety margin, which can then be run down, if there are no unforeseen spending items or overoptimistic forecast errors, as the time by which the rule must be met approaches. Accumulating a large safety margin involves collecting tax revenue that is not spent (or, at least, is not spent for at least a couple of years after it is raised). This, in turn, reduces welfare, because we are consuming less today than we would like. And 'hard' fiscal rules tend to be asymmetrical: the present government fails to meet the golden rule and might have to raise taxes if the average current budget surplus over an economic cycle is not at least zero but does not fail to meet the rule if the average surplus is more than zero (although ending the cycle with a huge surplus might be politically unpopular and result in calls for lower taxes). This means that the deadweight losses arising from tax increases needed to meet a hard fiscal rule are not necessarily counterbalanced by welfare gains arising from tax cuts.

Of course, the safety margin is only required if past forecasts have generally been systematically overoptimistic or if the governments wants to increase the likelihood of meeting the rule to above $50 \%$. But, as Kilpatrick (2001) points out, "Once a set of fiscal rules is in place it will generally be better for credibility to meet the rules by a small margin rather than to miss by an equivalent amount, particularly when the rules are new. The Government in effect faces a reputational cost function which is asymmetric." Even if there is no theoretical reason why the combination of 'hard' fiscal rules and uncertainties should lead to caution and safety margins, the desire for credibility and the political reality of the difficulty of explaining 'failures' to meet rules is likely to make the two linked. As Figure 3.2 in Section 3 showed, the present Chancellor began the current economic cycle with an expected current budget surplus well in excess of what was required for a $50 \%$ chance of meeting the golden rule. A large part of the safety margin has been used up since then, due to both discretionary increases in spending and reductions in expected tax revenues.

There is no reason why a fiscal rule could not take a 'softer' form. For instance, the Chancellor could predict a current budget surplus of $\mathrm{X} \%$ of national income by a certain year (say, four years ahead). He or she could then adjust fiscal policy over the next three years to improve the chances of meeting the forecast. If, in the fourth year, he or she came within one standard deviation of the prediction, based on the standard errors of four-year-ahead forecasts of the current budget surplus, then the rule would be have been met. If he or she missed it by more, the chancellor would write an 'open letter' or read to Parliament a statement explaining why the original forecast and outturn had differed. So the 'fiscal rule' would be that the chancellor should aim for a current budget surplus within a certain band of a central target (the band being determined with reference to forecasting uncertainties) and provide an explanation for straying outside the band. Although such a rule would not enable the chancellor to distinguish between 'hitting' and 'missing' targets, it would still have the same effect of generally ensuring that the public finances were in line with the government's stated objectives. The symmetrical nature of the band should reduce the tendency to err on the side of overachievement and make suboptimal tax and spending decisions to acquire a safety margin, because 
excessive overachievement (ie, a current budget surplus that was much too large) would be penalised as much as underachievement.

Someone in favour of the present interpretation of the golden rule could claim that the distinction between 'hard' and 'soft' rules is merely a question of semantics. For example, one might argue that the golden rule could just as easily be interpreted as a requirement for an average current budget surplus over the economic cycle of $1 \%$ of national income with a symmetrical band of $1 \%$ of national income on either side, leaving anything between $0 \%$ and $+2 \%$ of national income within the acceptable range. But the reality is that with the current hard target, there is a huge difference between perceptions of a marginal success (eg, achieving an average of $+0.001 \%$ ) and a marginal failure (eg, achieving $-0.001 \%$ ). There is a clear dividing line between the acceptable and the unacceptable, with a large margin of failure being regarded in the same way as a tiny one. By contrast, a softer rule aims to reflect the idea that a certain degree of imprecision is almost inevitable. The bands around the target indicate what degree of imprecision is considered acceptable, but the message remains that there are no guarantees of hitting targets and small deviations are preferable to large ones.

\section{What the present fiscal rules imply about priorities among the principles}

Kilpatrick's article implies that the Treasury understood the tradeoffs between the alternative types of fiscal rule when the golden rule and sustainable investment rule were decided upon. In his conclusions, he states, "two trade-offs are of particular importance in calibrating a fiscal system. First, between transparency and the rigidity of the fiscal rules: a greater degree of transparency may imply less need for rigid rules. Second, between the rigidity of the fiscal rules and the extent of tax and/or spending smoothing. The more rigid the rules the less scope there will be for smoothing tax or spending in the face of shocks."

With respect to the golden rule in particular, the government appears to have prioritised rigidity over flexibility or 'smooth-ability'. Placing a definite lower limit on the average current budget balance over the course of an economic cycle is considerably more rigid than, say, the 'aiming for within a range' approach mentioned above. The government has chosen a retrospective, 'hard' rule, on which clear judgement can be passed - which suggests that a considerable priority was placed on credibility when the golden rule was formulated. The fact that the Chancellor has continued to emphasis the importance that he places on meeting the golden rule, even during recent years in which his room for manoeuvre has been reduced greatly, lends further weight to the suggestion that credibility is a pre-eminent concern: rather than treating the golden rule as a 'rule of thumb' and allowing the possibility that not meeting the rule might be optimal, the Chancellor has elevated the status of the rule and staked his personal reputation on meeting it.

The danger of this emphasis on credibility is that it can result in excessive caution. Hemming and Kell (2001), in an article about promoting fiscal responsibility, write:

"[One] way of responding to the trade off between flexibility and credibility is to uses cautious projections for trend growth to reduce the risk of being overly optimistic in adjusting for the cycle. However, while this 
approach may be helpful in establishing the credibility of a new rules-based regime, its effectiveness will diminish over time as markets and voters learn to discount the deliberate margin for caution. Moreover, persistently cautious projections can result in the build-up of considerable room for manoeuvre, thereby limiting the credibility gains from a rule."

It is true that, to increase the chances of meeting the rule without having to resort to sudden changes in taxes and spending (ie, to balance credibility with flexibility and stability), the Chancellor chose to aim to overachieve the rule at the start of the economic cycle and to use cautious forecasting methods, as was discussed in Section 3 above. But this "precautionary saving", as Kilpatrick describes it, proved necessary because of the subsequent worse fiscal situation. (If the cyclically adjusted current budget surplus in 1999 and 2000 had been zero - ie, if there had not been any fiscal tightening over and above that of a standard economic cycle - then the Chancellor would now be on course to miss the golden rule over the current economic cycle.) Nevertheless, Hemming and Kell's warning about the unfortunate effects of excessive caution remains valid. Had the Treasury's forecasts from 1999, 2000 and 2001 been correct, the Chancellor would have ended the cycle in 2005-06 with a huge current budget surplus and a higher tax take than was necessary. For example, the 2001 Budget forecast that the cumulative cash value of the current budget surpluses over the whole economic cycle would be about $f_{1} 100 \mathrm{bn}$.

It will be interesting to see whether, if the golden rule is in place for longer, its credibility will increase, allowing the Chancellor to reduce the expected likelihood of meeting the rule at the start of the cycle. This might allow a lower tax burden without reducing spending, but would require him to accept a greater possibility that the rule could be broken. Alternatively, either this Chancellor or a successor could move from the present retrospective, 'hard', asymmetrical rule to a prospective, softer, symmetrical rule. This would minimise the chances of being required by a fiscal rule to take inefficient policy choices but might lack the political appeal of a clearer, 'hit or miss' target. 


\section{Conclusions}

In 1998 the UK government legislated the Code for Fiscal Stability which established the framework within which fiscal policy is now set. The UK is not alone in introducing such a code - many other developed countries such as New Zealand, Australia and Canada has also set up similar arrangements in recent years. More formalised monetary frameworks have also become more common in recent years. However, while there is an economic literature that suggests a credible monetary framework could make meeting certain targets easier, this is not the case with fiscal policy. While lowering individuals expectations of inflation could help to lower future inflation (for example through lower wage demands) there is not an obvious analogy for fiscal policy: if individuals expect government borrowing to be lower, this does not in itself directly lower future government borrowing.

Introducing a code, such as that in the UK, does not therefore appear to make it easier for a Government to achieve its policy objectives. However a well-set out code for fiscal policy can make it easier for a government to gain credibility over its economic policies, and there may be little cost to committing to practices that were going to be adhered with anyway. In practice it is also the case that given that the UK now has a code in place it might be very difficult for a future government to remove or substantially loosen the code without significant loss to its economic credibility.

The UK's current Code for Fiscal Stability focuses on five principles to which fiscal policy should be set: transparency, stability, responsibility, fairness and efficiency. These are important objectives. But in practice there may be times when they will not be fully compatible. For example, considering efficiency, stability and fairness:

- Efficiency is not necessarily compatible with stability, as a surprise policy might be more effective than a predictable one.

- Stability is not necessarily compatible with fairness, as a policy likely to lead to high and stable levels of growth and employment might be deemed to place an unfair burden on a particular group of individuals.

- Fairness is not necessarily compatible with efficiency, as a policy that increased support for a deserving group might be deemed to be inefficient.

Overall, the Code is not helpful at explaining which of the five principles are the priorities when it is not possible to achieve all of them. This is not necessarily a failing: the importance of, for example, fairness relative to efficiency is a political choice that may vary from government to government. But it might appropriate for the code to be explicit about the fact that some things might be achieved at the expense of others.

In terms of the five areas in which the code operates, many aspects are working well. There are also a number of areas where Government policy has gone further than the requirements of the code. This is welcome, as it would not be desirable for the CFS to lower standards to a minimum. However in many cases it would seem appropriate for the Code to explicitly require what the Government has been voluntarily providing. For 
example, the Treasury now publishes in each Budget the contracted payments to PFI providers for each of the next 25 years. There seems to be no reason why this voluntary practice should not be made mandatory.

There are areas where compliance with the Code for Fiscal Stability would not necessarily imply compliance with the IMF's "Revised Code of Good Practices on Fiscal Transparency". For instance, the Code states that the Treasury should make a number of key assumptions available for audit whereas the IMF code states that this should be the case for "all underlying assumptions". It would be more transparent and potentially more responsible to have all main assumptions publicly available, or at least independently audited, as otherwise there is always the possibility that non-disclosed assumptions could be less cautious than those that are disclosed. In terms of what is actually contained in the current version of the Code for Fiscal Stability, as opposed to what could potentially be included, the greatest concern is with a clause in the transparency section. It would be not be keeping with the principle of transparency for a government to not provide information on the basis that it "harm[ed] the integrity of the decision-making and policy advice processes in Government" and this clause should be removed from the Code.

While the Code for Fiscal Stability requires the Treasury to publish "an indication of past forecast errors for aggregates" we have shown that it would be relatively easy for the Treasury to place probability bands on its fiscal projections in a similar way to the Bank of England does with its projections for inflation. Indeed the National Institute of Social and Economic Research (NIESR) already follows a similar practice with its own quarterly forecasts. Using the Budget 2004 prediction of public sector net borrowing of $1.9 \%$ of national income in 2007-08 our own analysis suggests that on unchanged policies there is a $10 \%$ chance that it would be in excess of $6.5 \%$ of national income and a $10 \%$ chance that there will be a surplus of more than $2.7 \%$ of national income.

This type of analysis would hopefully help focus the debate away from whether particular point estimates of future borrowing were 'right' or 'wrong' and towards debate over whether an appropriate level of caution had been maintained. For example, taking the Chancellor's "golden rule", the April 2002 Budget forecast that this would be met with a cumulative surplus on the current budget of $7.9 \%$ of national income between April 1999 and March 2006. The April 2003 Budget forecast that this would be 2.9\% of national income and the March 2004 Budget just $0.7 \%$ of national income. In terms of the likelihood that the golden rule would be met without subsequent tax increases or spending cuts, our analysis suggests that in April 2002 there was an $82 \%$ chance that it would be met; that this only fell to 74\% by April 2003 despite the large fall in expected cumulated surpluses; but that there is now only a $60 \%$ chance on the basis of the Treasury's forecasts that the golden rule will be met over the current economic cycle.

The principles underlying the Code can also be used to provide guidelines over the choice and assessment of fiscal rules. The greater the clarity over precisely what measure and what period a rule is being assessed, and how the Government will respond if a rule looks set to be broken, the less likely it is that changes in fiscal policy come as a surprise, which should aid stability. There is also a clear trade-off between stability (which might be best served through more flexible rules) and perceived responsibility (which might be 
enhanced by more rigid rules). Once credibility in a fiscal framework has been established it may be appropriate to adopt a less cautious and more flexible approach.

\section{References}

Atkinson, T. (2004), Atkinson Review: Interim report, Measurement of Government Output and Productivity for the National Accounts, London: TSO (http://www.statistics.gov.uk/about/methodology by theme/atkinson/downloads/atki nson.pdf).

Balls, E. and O'Donnell, G. (2002), Reforming Britain's Economic and Financial Policy: Towards Greater Economic Stability, Palgrave.

Bank of England (2004), Quarterly Bulletin Spring 2004, Vol. 44, no. 1, London, March 2004 (http://www.bankofengland.co.uk/qb/qb0401.pdf).

Basu, S., Emmerson, C. and Frayne, C. (2003), An examination of the IFS Corporation Tax forecasting record, IFS Working Paper 03/21, London, 2003 (http://www.ifs.org.uk/workingpapers/wp0321.pdf).

Blow, L., Hawkins, M., Klemm, A., McCrae, J. \& Simpson, H. (2002), Budget 2002: Business Taxation Measures, IFS Briefing Note no. 24, London, May 2002 (http://www.ifs.org.uk/corpact/bn24.pdf).

Buiter, W. (2001), 'Notes on 'A Code for Fiscal Stability”, Oxford Economic Papers, vol. 53, pp. 1-19.

Chote, R., Emmerson, C. and Oldfield, Z. (eds, 2004), The IFS Green Budget: January 2004, IFS Commentary 95, London (http://www.ifs.org.uk/gbfiles/gb2004.shtml)

Congressional Budget Office (2003), The uncertainty of Budget projections: a discussion of data and methods, CBO report (tp:// ftp.cbo.gov/41xx/doc4195/04-23-UncertaintyFinal.pdf).

Department for Work and Pensions, The Pension Credit: Long-Term Projections, London, 2002 (www.dwp.gov.uk/publications/dwp/2002/pencred/pencred.pdf).

Dilnot, A., Emmerson, C. and Simpson, H. (eds, 2002), The IFS Green Budget: January 2002, IFS Commentary 87, London (http://www.ifs.org.uk/gb2002/chap3.pdf).

Emmerson, C., Frayne, C. and Love, S. (2004), The government's fiscal rules, Briefing Note No. 16/01. London: Institute for Fiscal Studies (http://www.ifs.org.uk/public/bn16.pdf).

Emmerson, C., McNally, S. and Meghir, C. (2004), 'Economic Evaluation of Education Initiatives', in Machin, S. and Vignoles, A. (eds), What's the Good of Education? The Economics of Education in the UK, Princeton University Press, forthcoming.

Giles, C. and Hall, J. (1998), 'Forecasting the PSBR Outside Government: The IFS Perspective', Fiscal Studies, vol. 19, no. 1, pp. 83-100. (http://www.ifs.org.uk/publications/fiscalstudies/fscj.pdf). 
Government Actuary's Department (2003), Government Actuary's Quinquennial Review of the National Insurance Fund as at April 2000, October 2003, London: GAD (http://www.gad.gov.uk/publications/docs/qr5-fullreport.pdf).

Haldane (2000), Ghostbusting: The UK Experience of Inflation Targeting, International $\begin{array}{llll}\text { Monetary } & \text { Fund } & \text { March }\end{array}$ (http://www.imf.org/external/pubs/ft/seminar/2000/targets/Haldane.pdf).

Hemming, R. \& Kell, M. (2001), 'Promoting fiscal responsibility: transparency, rules and independent fiscal authorities', IMF, published in Fiscal Rules, Banca d'Italia Research Department Public Finance Workshop, 2001.

HM Stationery Office (1998), Finance Act 1998, London (http://www.hmso.gov.uk/acts/acts1998/19980036.htm).

HM Treasury (1998), The Code for Fiscal Stability, London: HMT (http://www.hmtreasury.gov.uk/media//9F339/fiscal stability.pdf).

HM Treasury (1999a), Budget 1999, HC 298, London, March 1999 (http://archive.treasury.gov.uk/budget/1999/index.html).

HM Treasury (1999b), Analysing UK Fiscal Policy, London, November 1999 (http://www.hm-treasury.gov.uk/media//89A63/90.pdf).

HM Treasury (2000), Spending Review 2000, Cm 4807, London, July 2000 (http://www.hm-

treasury.gov.uk/Spending Review/Spending Review 2000/spend sr00 index.cfm).

HM Treasury (2001a), Budget 2001, HC 279, London, March 2001 (http://www.hmtreasury.gov.uk/Budget/Budget 2001/bud bud01 index.cfm).

HM Treasury (2001b), Pre-Budget Report, Cm 5318, London, November 2001 (http://www.hm-

treasury.gov.uk/Pre Budget Report/prebud pbr01/prebud pbr01 index.cfm).

HM Treasury (2002), Budget 2002, HC 592, London, April 2002 (http://www.hmtreasury.gov.uk/budget/bud bud02/budget report/bud bud02 repindex.cfm).

HM Treasury (2003a), Budget 2003, HC 500, London, April 2003 (http://www.hmtreasury.gov.uk/Budget/bud bud03/bud bud03 index.cfm).

HM Treasury (2003b), End of year fiscal report, London, December 2003 (http://www.hmtreasury.gov.uk/pre budget report/prebud pbr03/assoc docs/prebud pbr03 adend.c $\underline{\mathrm{fm}})$.

HM Treasury (2004), Budget 2004, HC 301, London, March 2004 (http://www.hmtreasury.gov.uk/budget/budget 04/budget report/bud bud04 repindex.cfm).

IMF (2001), Revised Code of Good Practices on Fiscal Transparency, February 2001 (http://www.imf.org/external/np/fad/trans/code.pdf).

$\begin{array}{llll}\text { IMF (2004), Public-Private } \quad \text { Partnerships, } & \text { March }\end{array}$ (http://www.imf.org/external/np/fad/2004/pifp/eng/031204.htm). 
Kilpatrick, A. (2001), 'Transparent frameworks, fiscal rules and policy-making under uncertainty', HM Treasury, published in Fiscal Rules, Banca d'Italia Research Department Public Finance Workshop, 2001.

Marshall, C. (1998), 'Economic Instruments and the Business Use of Energy', London: HMT, November 1998 (http://archive.treasury.gov.uk/pub/html/prebudgetNov98/marshall.pdf).

National Audit Office (2002), Audit of Assumptions for the 2002 Budget, HC 760, London, April 2002 (http://www.nao.org.uk/publications/nao reports/01-02/0102760.pdf).

National Audit Office (2003), Audit of Assumptions for Budget 2003, HC 627, London, April 2003 (http://www.nao.org.uk/publications/nao reports/02-03/0203627.pdf).

Robinson, M. (1998), 'Measuring Compliance with the Golden Rule', Fiscal Studies, vol. 19 , no. 4 , pp. 447-462. (http://www.ifs.org.uk/publications/fiscalstudies/robinson nov98.pdf). 


\section{Appendix A. Relationship in the distribution errors in forecasting the Current Budget surplus and Public Sector Net Borrowing.}

Let PSNB ${ }^{e}, \mathrm{CBS}^{\mathrm{e}}$ and $\mathrm{PSNI}{ }^{\mathrm{e}}$ be the error on forecasting PSNB, Current budget surplus and PSNI respectively. Therefore:

$\mathrm{PSNB}^{\mathrm{e}}=\mathrm{PSNI}^{\mathrm{e}}-\mathrm{CBS}^{\mathrm{e}}$

1. Is the mean CBS error the same as minus the mean PSNB error?

Mean $\left(\mathrm{PSNB}^{\mathrm{e}}\right) \quad=$ Mean $\left(\mathrm{PSNI}^{\mathrm{e}}-\mathrm{CBS}^{\mathrm{e}}\right)$

$=$ Mean $(\mathrm{PSNI})-$ Mean $\left(\mathrm{CBS}^{\mathrm{e}}\right)$

Therefore Mean $\left(\mathrm{PSNB}^{\mathrm{e}}\right) \quad=-$ Mean $\left(\mathrm{CBS}^{\mathrm{e}}\right)$ if and only if Mean $(\mathrm{PSNI})=0$

As there is no reason to believe that the forecasts of public sector net investment have a tendency to be biased upwards or downwards this should be a reasonable assumption to make.

2. Is the variance of the CBS error the same as the variance of the PSNB error?

$$
\begin{aligned}
\operatorname{Var}\left(\mathrm{PSNB}^{\mathrm{e}}\right) & =\operatorname{Var}\left(\mathrm{PSNI}^{\mathrm{e}}-\mathrm{CBS}^{\mathrm{e}}\right) \\
& =\operatorname{Var}\left(\mathrm{PSNI}^{\mathrm{e}}\right)+\operatorname{Var}\left(\mathrm{CBS}^{\mathrm{e}}\right)-2 \text { covariance }\left(\mathrm{PSNI}^{\mathrm{e}}, \mathrm{CBS}^{\mathrm{e}}\right)
\end{aligned}
$$

Therefore $\operatorname{Var}\left(\mathrm{PSNB}^{\mathrm{e}}\right)=\operatorname{Var}\left(\mathrm{CBS}^{\mathrm{e}}\right)$ if and only if:

$$
\begin{aligned}
\operatorname{Var}(\mathrm{PSNI}) & =2 \text { covariance }\left(\mathrm{PSNI}^{\mathrm{e}}, \mathrm{CBS}^{\mathrm{e}}\right) \\
& \left.=2 * p^{*} \mathrm{sd}(\mathrm{PSNI})^{*} \mathrm{sd}^{(\mathrm{CBS})}\right)
\end{aligned}
$$

So true if:

$$
\begin{aligned}
& \operatorname{Var}\left(\mathrm{PSNI}^{\mathrm{e}}\right)=0 \\
& \text { or } \\
& \operatorname{sd}\left(\mathrm{PSNI}^{\mathrm{e}}\right)=2 * p^{*} \operatorname{sd}\left(\mathrm{CBS}^{\mathrm{e}}\right)
\end{aligned}
$$

Neither of these conditions are liked to be satisfied.

Assuming that the covariance between $\mathrm{CBS}^{\mathrm{e}}$ and $\mathrm{PSNI}^{\mathrm{e}}$ is equal to zero then:

$$
\operatorname{Var}\left(\mathrm{CBS}^{\mathrm{e}}\right) \quad=\operatorname{Var}\left(\mathrm{PSNB}^{\mathrm{e}}\right)-\operatorname{Var}\left(\mathrm{PSNI}^{\mathrm{e}}\right)
$$

This implies that the variance of the forecasting error on the current budget surplus will be lower than the variance of the forecasting error on public sector net borrowing. This implies that by using Var (PSNBe) in Figure 3.2 we will be understating the likelihood that the golden rule will be met on unchanged policies over the current economic cycle. However to the extent that $\operatorname{Var}\left(\mathrm{PSNI}^{\mathrm{e}}\right)$ is small relative to $\operatorname{Var}\left(\mathrm{PSNB}^{\mathrm{e}}\right)$ in practice this bias is likely to be relatively small. Evidence from recent years suggests that this is the case. 